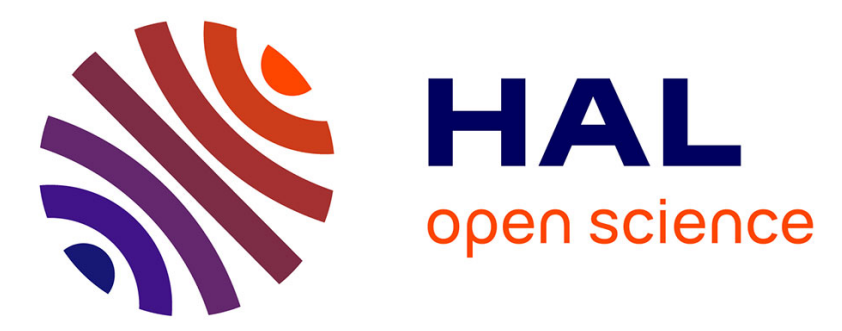

\title{
Reexcitation mechanisms in epicardial tissue: Role of I density heterogeneities and I inactivation kinetics
}

\author{
Inma R. Cantalapiedra, Angelina Peñaranda, Lluis Mont, Josep Brugada,
} Blas Echebarria

\section{- To cite this version:}

Inma R. Cantalapiedra, Angelina Peñaranda, Lluis Mont, Josep Brugada, Blas Echebarria. Reexcitation mechanisms in epicardial tissue: Role of I density heterogeneities and I inactivation kinetics. Journal of Theoretical Biology, 2009, 259 (4), pp.850. 10.1016/j.jtbi.2009.04.021 • hal-00554606

\section{HAL Id: hal-00554606 https://hal.science/hal-00554606}

Submitted on 11 Jan 2011

HAL is a multi-disciplinary open access archive for the deposit and dissemination of scientific research documents, whether they are published or not. The documents may come from teaching and research institutions in France or abroad, or from public or private research centers.
L'archive ouverte pluridisciplinaire HAL, est destinée au dépôt et à la diffusion de documents scientifiques de niveau recherche, publiés ou non, émanant des établissements d'enseignement et de recherche français ou étrangers, des laboratoires publics ou privés. 


\section{Author's Accepted Manuscript}

Reexcitation mechanisms in epicardial tissue: Role of $\mathrm{I}_{\text {to }}$ density heterogeneities and $\mathrm{I}_{\mathrm{Na}}$ inactivation kinetics

Inma R. Cantalapiedra, Angelina Peñaranda, Lluis Mont, Josep Brugada, Blas Echebarria

PII: S0022-5193(09)00193-3

DOI: doi:10.1016/j.jtbi.2009.04.021

Reference: YJTBI 5547

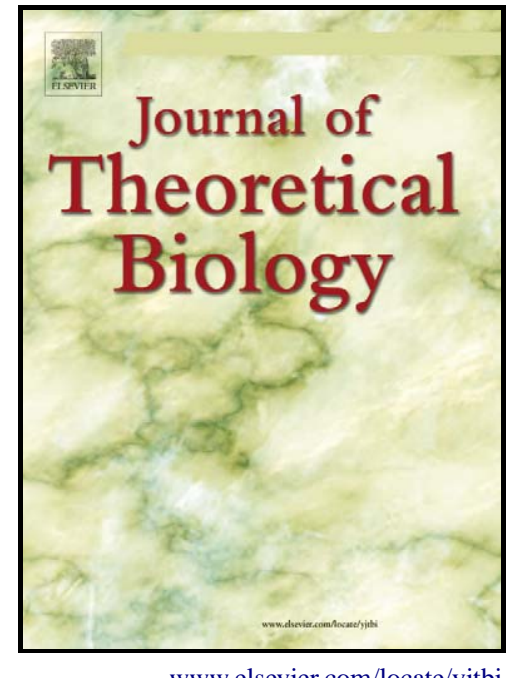

www.elsevier.com/locate/yjtb

To appear in: $\quad$ Journal of Theoretical Biology

Received date: $\quad 12$ February 2009

Revised date: $\quad 17$ April 2009

Accepted date: $\quad 23$ April 2009

Cite this article as: Inma R. Cantalapiedra, Angelina Peñaranda, Lluis Mont, Josep Brugada and Blas Echebarria, Reexcitation mechanisms in epicardial tissue: Role of $\mathrm{I}_{\text {to }}$ density heterogeneities and $\mathrm{I}_{\mathrm{Na}+}$ inactivation kinetics, Journal of Theoretical Biology, doi:10.1016/j.jtbi.2009.04.021

This is a PDF file of an unedited manuscript that has been accepted for publication. As a service to our customers we are providing this early version of the manuscript. The manuscript will undergo copyediting, typesetting, and review of the resulting galley proof before it is published in its final citable form. Please note that during the production process errors may be discovered which could affect the content, and all legal disclaimers that apply to the journal pertain. 


\title{
Reexcitation Mechanisms in Epicardial Tissue: Role of $\mathbf{I}_{t_{0}}$ Density Heterogeneities and $\mathbf{I}_{\mathrm{Na}^{+}}$Inactivation Kinetics
}

\author{
Inma R. Cantalapiedra ${ }^{\mathrm{a}}$, Angelina Peñaranda $^{\mathrm{a} \dagger}$, Lluis Mont ${ }^{\mathrm{b}}$, Josep Brugada ${ }^{\mathrm{b}}$, Blas \\ Echebarria $^{\mathrm{a}^{*}}$ \\ ${ }^{a}$ Departament de Física Aplicada, Universitat Politècnica de Catalunya, Barcelona, Spain \\ ${ }^{\mathrm{b}}$ Cardiology Department, Thorax Institute, University of Barcelona, Barcelona, Spain
}

† These authors contributed equally to this study.

*Correspondence to Departament de Física Aplicada, Universitat Politècnica de Catalunya, EPSEB, 44-50 Av. Dr. Marañón, 08028 Barcelona, Spain. Email: blas@,fa.upc.edu. Tel.: +34 934017995. Fax.: +34 934017700 . 


\begin{abstract}
Dispersion of action potential repolarization is known to be an important arrhythmogenic factor in cardiopathies such as Brugada Syndrome. In this work, we analyze the effect of a variation in sodium current $\left(\mathrm{I}_{\mathrm{Na}}\right)$ inactivation and a heterogeneous rise of transient outward current $\left(\mathrm{I}_{\mathrm{to}}\right)$ in the probability of reentry in epicardial tissue. We use the Luo-Rudy model of epicardial ventricular action potential to study wave propagation in a one-dimensional fiber. Spatial dispersion in repolarization is introduced by splitting the fiber into zones with different strength of $I_{t o}$. We then analyze the proarrhythmic effect of a variation in the relaxation time and steady-state of the sodium channel fast inactivating gate $\mathrm{h}$. We quantify the probability of reentry measuring the percentage of reexcitations that occurs in 200 beats. We find that, for high stimulation rates, this percentage is negligible, but increases notably for pacing periods above $700 \mathrm{~ms}$. Surprisingly, with decreasing $\mathrm{I}_{\mathrm{Na}}$ inactivation time, the percentage of reexcitations does not grow monotonically, but presents vulnerable windows, separated by values of the $\mathrm{I}_{\mathrm{Na}+}$ inactivation speed-up where reexcitation does not occur. By increasing the strength of L-type calcium current $\mathrm{I}_{\mathrm{CaL}}$ above a certain threshold, reexcitation disappears. Finally, we show the formation of reentry in stimulated two-dimensional epicardial tissue with modified $\mathrm{I}_{\mathrm{Na}+}$ kinetics and $\mathrm{I}_{\mathrm{to}}$ heterogeneity. Thus, we confirm that while $\mathrm{I}_{\mathrm{to}}$ dispersion is necessary for phase-2 reentry, altered sodium inactivation kinetics influences the probability of reexcitation in a highly nonlinear fashion.
\end{abstract}

Keywords: Brugada syndrome; Phase-2 reentry; Ventricular Fibrillation; Arrhythmia; Dispersion of refractoriness. 


\section{INTRODUCTION}

Ventricular fibrillation (VF), a state of turbulent electrical activity in the ventricles that impedes cardiac contraction, underlies most cases of sudden cardiac death. Typically it is preceded by a state of ventricular tachycardia (VT), generated by high frequency rotors (reentrant waves). The classical mechanism that has been suggested for the transition from VT to VF involves the breakup of a single rotor into multiple wavelets, generating a turbulent activity. The formation of rotors is often due to the existence of dispersion of AP repolarization in a region of cardiac muscle, so that propagation block is induced, generating a reentrant wave $(1,2)$. This heterogeneity may have several origins: ectopic beats, scarred tissue, alternans, ischemia, fibrosis, channelopathies, etc. Among the latter, an important example is Brugada syndrome (3) (responsible for at least $20 \%$ of sudden deaths in patients with structurally normal hearts (4) ). Since its discovery in 1992, it has been linked to more than 90 different mutations (5), including genes affecting the $\mathrm{Na}^{+}$and $\mathrm{Ca}^{2+}$ channels $(6,7)$. Particularly, between $10 \%$ and $30 \%$ of the cases of Brugada syndrome are related to mutations in the SCN5A gene (8), which encodes the $\alpha$-subunit of the voltage-gated sodium channel $\mathrm{Na}_{\mathrm{v}} 1.5$ (9). These mutations have been shown to result in loss of function of the sodium channel, giving rise to either reduced $\mathrm{Na}^{+}$channel conductance or a change in the voltage dependence and dynamics of $\mathrm{I}_{\mathrm{Na}+}$ activation, inactivation, or reactivation (10).

Clinically, Brugada syndrome is characterized by an abnormal elevation of the ST segment or an accentuated $J$ wave in the right precordial leads (V1-V3) of the ECG (3). This has been related to the early repolarization of the action potential (AP) of epicardial cells caused by the lack of function of the $\mathrm{Na}^{+}$channel. Since the strength of the transient outward potassium current $I_{t o}$ is larger in the epicardium (specially in the right epicardium) than in the 
endocardium, these alterations in the ECG could be due to transmural dispersion of AP repolarization. However, this alone does not give rise to an arrhythmogenic substrate (10). Rather, the substrate for reentry most probably appears when the action potential dome is lost at some epicardial sites but not at others, thus resulting in dispersion of repolarization within the epicardium. Reexcitation then takes place via phase 2 reentry $(10,11)$. The origin of this effect lies in the heterogeneous distribution of $\mathrm{I}_{\mathrm{to}}$ conductance, which varies not only transmurally from epicardium to endocardium, but also along the epicardium from apex to base (12). All together, this explanation of the arrhythmogenic substrate in Brugada syndrome is known as the 'repolarization disorder hypothesis'. Supporting this hypothesis, it has been observed in experiments in animal (13) and in silico models $(14,15,16)$ that heterogeneity in action potential duration, as present in Brugada syndrome, represents an essential arrhythmogenic factor. However, a point against this explanation is that, according to recent computer simulations with a Luo-Rudy model incorporating a SCN5A mutation (C1850S), a decrease in $\mathrm{Na}^{+}$channel functionality (through a change in the closing time of the inactivation gate $\mathrm{h}$ ) does not seem to produce a significant effect in repolarization (17). In fact, an alternative explanation for the ECG alterations observed in Brugada syndrome is that they are caused by slow conduction in the right ventricle. This has led to the idea that the arrhythmia may be generated by a conduction disorder leading to conduction block and reentry ('conduction disorder hypothesis').

In this work we study under what circumstances an extrasystole can be produced in the epicardium via a phase 2 reentry, in conditions of reduced $\mathrm{Na}^{+}$channel functionality, and heterogeneous distribution of APD. Thus, we want to study if the 'repolarization disorder hypothesis' alone could explain reentry in Brugada syndrome. We analyze this point by simulating a one-dimensional fiber (1-D) using a Luo-Rudy (LRd) model (18) of the 
epicardial ventricular action potential. To incorporate the effect of Brugada syndrome we consider an altered $\mathrm{I}_{\mathrm{Na}^{+}}$inactivation time dependence. Inhomogeneity is introduced into the model by splitting the fiber into zones with different $\mathrm{I}_{\text {to }}$ current density, thus creating spatial dispersion in repolarization. The number of reexcitations is then measured as a function of: 1) a variation in the dynamics of $\mathrm{I}_{\mathrm{Na}+}$ inactivation gate; 2) a rise of transient outward potassium current $\mathrm{I}_{\mathrm{to}} ; 3$ ) the strength of L-type $\mathrm{Ca}^{2+}$ conductance; and 4) the stimulation rate. Finally, simulations in a two-dimensional sheet of tissue are performed to exemplify the mechanism of reentry in this model.

\section{METHODS}

Model. We use the Luo-Rudy model (18) (LRd) to study the propagation of the action potential in ventricular myocites. The dynamics of the transmembrane potential, $V_{\mathrm{m}}$, is governed by the partial differential equation:

$$
\frac{\partial V_{m}}{\partial t}=-\frac{I_{i o n}}{C_{m}}+\nabla \cdot\left(D \nabla V_{m}\right)
$$

where $C_{\mathrm{m}}=1 \mu \mathrm{F} / \mathrm{cm}^{2}$ is the membrane capacitance, $D$ is the diffusion tensor and $\mathrm{I}_{\text {ion }}$ is the sum of ionic currents. The tissue is considered isotropic, with $D=1.5410^{-3} \mathrm{~cm}^{2} / \mathrm{ms}$. This value is taken to obtain a conduction velocity that resembles that observed in human myocardium. The total ionic current incorporates the modifications made by Dumaine et al (19) to include the effect of the transient outward current $I_{\text {to }}$ in epicardial cells, which is written as $I_{t o}=g_{\text {to }} z^{3} y$ $R(V)\left(V_{m}-E_{K}\right)$, where $E_{K}$ is the Nerst reversal potential for potassium ions; $R(V)=\exp (V / 100)$, the outward rectification factor for the channel; $g_{\text {to }}$, maximum conductance of the channel $(\mathrm{mS} / \mu \mathrm{F})$; and $\mathrm{z}$ and $\mathrm{y}$, activation and inactivation gates, respectively. In (19), a value of $\mathrm{g}_{\mathrm{to}}=1.1 \mathrm{mS} / \mu \mathrm{F}$ is set for epicardial cells. The heterogeneity related with the origin of a phase2 reentry is achieved by splitting the system into two zones with different strength of the 
transient outward potassium current $\mathrm{I}_{\mathrm{to}}$. In the $\mathrm{LRd}$ model $\mathrm{I}_{\mathrm{Na}}$ is formulated as $\mathrm{I}_{\mathrm{Na}}=\mathrm{g}_{\mathrm{Na}}$ $\mathrm{m}^{3} \mathrm{hj}\left(\mathrm{V}_{\mathrm{m}}-\mathrm{E}_{\mathrm{Na}}\right)$, where $\mathrm{g}_{\mathrm{Na}}$ is the $\mathrm{I}_{\mathrm{Na}}$ conductance $(16 \mathrm{mS} / \mu \mathrm{F}), \mathrm{E}_{\mathrm{Na}}$ the $\mathrm{Na}^{+}$Nerst potential, and $\mathrm{m}, \mathrm{h}$, and $\mathrm{j}$, the voltage dependent gates of activation, and fast and slow inactivation, respectively. We modify only the dynamics of the fast inactivation gate, given by

$$
\frac{d h}{d t}=\Gamma_{\alpha} \alpha_{h}(1-h)-\Gamma_{\beta} \beta_{h} h
$$

where the rate constants $\alpha_{\mathrm{h}}(V)$ and $\beta_{\mathrm{h}}(V)$ take the original values in the LRd model, and $\Gamma_{\alpha}$ and $\Gamma_{\beta}$ are two inactivation speed-up factors that we introduce. We have conducted simulations in which either inactivation, recovery from inactivation, or both, are affected by varying the speed-up factors $\Gamma_{\alpha}$ and $\Gamma_{\beta}$ from 1 (wild-type dynamics) to 10 , corresponding to different mutations in Brugada syndrome $(17,20,21,22,23)$. For completeness we have also studied the case where the dynamics of inactivation is slowed $\left(\Gamma_{\alpha}, \Gamma_{\beta}<1\right)$. In our notation the time constant for inactivation $\tau_{\mathrm{h}}$ and the steady-state value $\mathrm{h}_{\infty}$ of the gate $\mathrm{h}$ become

$$
\tau_{h}=\Gamma_{\alpha} \alpha_{h}+\Gamma_{\beta} \beta_{h}, \quad h_{\infty}=\frac{\Gamma_{\alpha} \alpha_{h}}{\Gamma_{\alpha} \alpha_{h}+\Gamma_{\beta} \beta_{h}}
$$

When both speed-up factors are equal then we define the parameter $\Gamma=\Gamma_{\alpha}=\Gamma_{\beta}$, that corresponds to a multiplicative factor of the time constant $\tau_{\mathrm{h}}$, without modifying the steadystate $\mathrm{h}_{\infty}$

Numerical method. Numerical simulations are performed on a 1-D epicardial fiber whose length is $3-4 \mathrm{~cm}$, and in an isotropic sheet of epicardial tissue of dimensions $\mathrm{Lx}=\mathrm{Ly}=4 \mathrm{~cm}$. In both cases non-flux boundary conditions are considered. The code we use is based on the single cell code in (24). Differential equations are solved in time by a forward Euler method with a temporal step of $\mathrm{dt}=0.01 \mathrm{~ms}$ and by finite differences in space with a step of $\mathrm{dx}=0.02$ $\mathrm{cm}$. To integrate the equations for the gating variables of the time dependent currents the 
Rush and Larsen scheme was used. We have checked that the number of reexcitations observed in the simulations does not change appreciably if we reduce the time and space steps.

Pacing protocol. We use two different pacing protocols for the 1-D fiber. In one, we pace the cable from one end. That is, we initiate excitations from regions with high or low $\mathrm{I}_{\text {to }}$ current density. Reexcitation may occur if the action potential loses the dome in the region with high $g_{\text {to }}$, resulting in a short action potential, that allows the system to recover quickly from refractoriness. This reexcitation will be orthodromic if the resulting pulse travels in the same direction as AP propagation, and antidromic otherwise. In the other, to simulate the fast transmural stimulation of epicardium, we pace all the tissue at the same time. This pacing protocol is then used to measure the percentage of reexcitations for given parameters. To do this, we first let the system stabilize by pacing it during 500 beats, and then measure the percentage of reexcitations that occur in the subsequent 200 beats. The reexcitations are measured in the middle of the region of the cable with high $g_{\text {to }}$. We consider that, after a repolarization (defined as the potential going below $-80 \mathrm{mV}$ ), a reexcitation has occurred when the transmembrane potential goes up again, at least reaching $-20 \mathrm{mV}$.

Action potential duration (APD) and conduction velocity (CV). To study how the $\mathrm{CV}$ and APD shapes change with stimulation period, $\mathrm{I}_{\text {to }}$ density, and $\mathrm{I}_{\mathrm{Na}}$ inactivation time constants, we compute the dynamic restitution curves. These are obtained by pacing a $4 \mathrm{~cm}$ fiber from one end during 500 beats to reach steady-state, after which we record the values of the action potential duration (APD) and conduction velocity (CV). 
Variation of parameters. We then study the probability of reexcitation as a function of the speed-ups $\Gamma_{\alpha}$ and $\Gamma_{\beta}$ (Eq. (1)) in the dynamics of the $\mathrm{Na}^{+}$inactivating gate, the spatial difference in the conductance of the transient outward potassium current $g_{\text {to }}$, and the strength of L-type calcium current $\mathrm{I}_{\mathrm{CaL}}$. Simulations are performed for pacing periods of $500 \mathrm{~ms}, 700$ $\mathrm{ms}$ and $1000 \mathrm{~ms}$.

\section{RESULTS}

Fig. 1 shows the effect of varying the parameters $\Gamma_{\alpha}$ and $\Gamma_{\beta}$ on $\tau_{\mathrm{h}}$ and $\mathrm{h}_{\infty}$. An increase in $\Gamma_{\alpha}$ produces a shift of the steady-state curve $h_{\infty}$ and the peak value of $\tau_{h}$ towards higher voltage values (Figs. 1A and B). The same change in $\Gamma_{\beta}$ produces the opposite effect (Figs. 1C and D), with a reduction of the maximum value of the probability of the open state (Fig. 1C), thus producing an effective reduction in the $\mathrm{Na}^{+}$conductance. When both parameters are modified in the same way $\left(\Gamma=\Gamma_{\alpha}=\Gamma_{\beta}\right)$ the steady-state curve is not affect and the time constant $\tau_{\mathrm{h}}$ is just reduced by a factor $\Gamma$.

To assess the effect of these modifications, we measure the action potential duration (APD) and conduction velocity $(\mathrm{CV})$ as a function of $\mathrm{I}_{\mathrm{to}}$ strength, $\mathrm{I}_{\mathrm{Na}}$ inactivation speed-up $\Gamma$, and pacing period BCL (Fig. 2). We observe that it takes a long interval of 200-300 s (at $\mathrm{BCL}=1 \mathrm{~s})$ to reach steady state in the ionic concentrations of intracellular $\mathrm{Na}^{+}$and $\mathrm{K}^{+}$. This has an important effect on the shape of the action potential (25). For instance, for $\mathrm{g}_{\mathrm{to}}=1.1$ $\mathrm{mS} / \mu \mathrm{F}$ and $\Gamma=3$ (normal $g_{\text {to }}$ for epicardium and accelerated $\mathrm{Na}^{+}$inactivation kinetics), the ionic concentrations change from their initial values of $\left[\mathrm{Na}^{+}\right]_{\mathrm{i}}=12.24 \mathrm{mM}$ and $\left[\mathrm{K}^{+}\right]_{\mathrm{i}}=136.9$ $\mathrm{mM}$, to $\left[\mathrm{Na}^{+}\right]_{\mathrm{i}} \sim 14.25 \mathrm{mM}$ and $\left[\mathrm{K}^{+}\right]_{\mathrm{i}} \sim 134.4 \mathrm{mM}$. Then, while the initial APs maintain the dome (Fig. 2A), they start to lose it after a few minutes of pacing and accumulation of $\mathrm{Na}^{+}$ (Fig. 2B). To ensure that the stationary state is reached, the fiber is paced 500 times before 
the APD and CV are measured. In Figs. $2 \mathrm{C}$ and $2 \mathrm{D}$ we show the average value and the standard deviation (bars) of the following 100 APDs. The corresponding percentage of domeless APs is shown in Figs. $2 \mathrm{E}$ and $2 \mathrm{~F}$. For $\mathrm{g}_{\mathrm{to}}=1.3 \mathrm{mS} / \mu \mathrm{F}$, there is an alternation between APDs with and without dome, with a rather large dispersion in the values of the APD (Figs. $2 \mathrm{C}$ and $2 \mathrm{E})$. As $\Gamma$ is increased, the number of domeless APDs increases, until for $\Gamma$ larger than 4 all of them lose the dome (Fig. 2E). By contrast, for $g_{\mathrm{to}}=0.8 \mathrm{mS} / \mu \mathrm{F}$, a change in $\mathrm{I}_{\mathrm{Na}^{+}}$ inactivation does not seem to affect the APD very much, except for a slight increase with $\Gamma$ (Fig. 2C). For a given $\Gamma$, an increase in the value of $g_{\text {to }}$ can induce the loss of the dome (Fig. 2D and $2 \mathrm{~F}$ ), as expected. A change in $\mathrm{I}_{\mathrm{Na}}$ inactivation has also a significant effect on $\mathrm{CV}$, ranging from $65 \mathrm{~cm} / \mathrm{s}$ at normal inactivation to around $30 \mathrm{~cm} / \mathrm{s}$ at inactivation rates 6 times faster than normal (Fig. 2G). A change of $g_{\text {to }}$, on the other hand, has a negligible effect on CV (Fig. 2H).

To study reexcitation, we consider a fiber split into two regions with different values of $\mathrm{I}_{\text {to }}$ conductance $g_{\text {to }}$, as shown in Fig. 3. In the region with lower value of $g_{\text {to }}$, the effect of shorter sodium current inactivation time is just to accentuate the notch in phase 2 of the AP (Fig. 3A), while in the region of larger $g_{\text {to }}$ it can cause the loss of the dome (Fig. 3B). However, this is not always enough to produce reexcitation (Figs. 3C and 3E). Typically, as the pulse goes from the region with large $g_{\text {to }}$ to the region of small $g_{\text {to }}$, it recovers the dome. The subsequent entrance of calcium current $\mathrm{I}_{\mathrm{CaL}}$ increases the transmembrane potential, which diffuses back to the region of large $g_{\text {to }}$, resulting in a delayed dome (an early afterdepolarization (EAD)). Depending on the $\mathrm{I}_{\mathrm{CaL}}$ current, diffusion and inactivation time, this delayed dome can, in fact, give rise to a reexcitation ( $\mathrm{I}_{\mathrm{Na}+}$ entrance). When pacing from one end of the cable the reexcitation can be either antidromic (reflection, Fig. 3D) or orthodromic (reexcitation, Fig. $3 F)$, depending on which side has the largest value of $g_{\text {to }}$. 
In Fig. 4 we reproduce the same simulation as in Fig. 3D, but showing also the L-type calcium current $I_{C a L}$, and the two gates of $I_{\mathrm{Na}^{+}}$inactivation. We observe that $\mathrm{I}_{\mathrm{Na}+}$ is never triggered at the point of the fiber where there is a jump of $g_{\text {to. }}$ At that point, rather, the recovery of the dome in the region with lower $g_{\text {to }}$ produces a gradient of transmembrane voltage that activates $\mathrm{I}_{\mathrm{CaL}}$ in the adjacent region of high $\mathrm{g}_{\text {to. }}$. Spatially, this results in a retrograde front in voltage that propagates slowly into the region of high $\mathrm{g}_{\text {to }}$ due to the recruitment of $\mathrm{Ca}^{++}$channels (Figs. 4F-H). This proceeds until a point of the tissue is reached at which the sodium gates $\mathrm{h}$ and $\mathrm{j}$ have had enough time to recover, producing an influx of $\mathrm{I}_{\mathrm{Na}+}$ and a fast retrograde depolarization pulse (Fig. 4I).

To have a better idea of the influence of different parameters on the probability of reexcitation, we perform simulations in which we stimulate all tissue at the same time. We pace the fiber 500 times to reach steady state, and then we measure the number of reexcitations in the following 200 beats. For normal stimulation rates, the percentage of reexcitations is negligible, even for large values of $\Gamma$ (fast inactivation). It is not until the pacing period reaches $1000 \mathrm{~ms}$ that the percentage of reexcitations increases notably (Fig. 5A). One interesting thing to notice is that this percentage does not grow monotonically as the time constant for $\mathrm{I}_{\mathrm{Na}+}$ inactivation is decreased ( $\Gamma$ is increased), but there are vulnerable windows separated by values of the sodium inactivation speed-up $\Gamma$, where the probability of reexcitation again becomes very small (Fig. 5B). This same behavior is observed for different pairs of values of $g_{\text {to }}$ in the two regions of tissue (Fig. 5C).

One hint on the origin of these windows can be obtained studying separately the effect of a variation in the $\mathrm{h}$ gate opening and closing (obtained modifying the parameters $\Gamma_{\alpha}$ and $\Gamma_{\beta}$ in 
Eq. 1). An increase in $\Gamma_{\alpha}$ (Fig. 6A) increases slightly the probability of reexcitations, due to the faster recovery of the $\mathrm{h}$ gate. A similar increase in $\Gamma_{\beta}$ (Fig. 6B), however, has a more complex effect, resulting in a non-monotonous change in the reexcitation, with regions where it is completely absent. This may be due to two competing effects: by one hand, an increase in $\Gamma_{\beta}$ produces a faster inactivation of $\mathrm{I}_{\mathrm{Na}}$ and favors, therefore, the loss of dome necessary to obtain a reexcitation. By the other hand, it pushes the steady-state value of $\mathrm{h}$ towards lower values of the voltage, thus impeding reactivation and reducing the strength of $\mathrm{I}_{\mathrm{Na}+}$, which hinders reexcitation.

Since the loss of dome is produced by a reduction in the entrance of $\mathrm{I}_{\mathrm{CaL}}$, we study the effect of varying calcium current strength, obtained multiplying $\mathrm{I}_{\mathrm{CaL}}$ by a given constant factor. In Fig. 7 we show the percentage of reexcitations as a function of calcium current strength, for various values of the $\mathrm{I}_{\mathrm{Na}+}$ inactivation speed-up $\Gamma$. Decreasing $\mathrm{I}_{\mathrm{CaL}}$, reexcitation is more unlikely since the entrance of $\mathrm{I}_{\mathrm{CaL}}$ in the low $g_{\text {to }}$ region is not large enough to reexcite the adjacent tissue. Furthermore, as $\mathrm{I}_{\mathrm{CaL}}$ is decreased, the AP loses the dome even in the low $g_{\text {to }}$ region, which reinforces this trend. Increasing $\mathrm{I}_{\mathrm{CaL}}$, on the other hand, has at first a proarrhythmic effect, until a limit is reached at which the AP in the high $g_{\text {to }}$ region recovers the dome, and dispersion of repolarization is lost. In Table I we summarize the effects of different parameter changes.

In two-dimensional epicardial tissue the heterogeneity in action potential duration can give rise to reentry. In Fig. 8 we show such a case in epicardial tissue stimulated all at once (at a pacing period of $\mathrm{BCL}=1000 \mathrm{~ms}$ ). In the lower pannels we show the time evolution of the transmembrane voltage at given points in the tissue, while the upper pannels show different voltage snapshots taken every $50 \mathrm{~ms}$ during the third stimulation, except for the last one that corresponds to the ensuing turbulent state some time after. As in a cable with a distribution of 
$\mathrm{I}_{\mathrm{to}}$ density, in a patch of tissue there is also an alternation of dome and domeless APs in the region of high $g_{\text {to }}$. For the parameters in the figure $\left(\Gamma=4, g_{\text {to }}=1.3 \mathrm{mS} / \mu \mathrm{F}\right.$ and $\left.1.1 \mathrm{mS} / \mu \mathrm{F}\right)$, reexcitations are frequent during the beats when the dome is lost. It must be noted, however, that the area where the APs maintain the dome must be such that it breaks symmetry, in order to generate reentry. In our simulations this is achieved choosing a triangular shape. It should be noted that, once reentry is originated it may either disappear, result in a sustained rotor, or in a disordered state with multiple rotors. For this, both the reduction in conduction velocity and the position and geometry of the inhomogeneities may play a fundamental role (26). A systematic study of this point, however, is beyond the scope of the present paper.

\section{DISCUSSION}

Phase-2 reentry is a basic mechanism to explain the creation of reentrant waves and the transition to polymorphic VT and VF. In this work we study the proarrhythmic effect of heterogeneity in $\mathrm{I}_{\mathrm{to}}$ expression in epicardial tissue with modified sodium channel kinetics. This is implemented by splitting an epicardial fiber into two zones with different value of $\mathrm{I}_{\text {to }}$ conductance. To simulate the fast transmural stimulation of the epicardium, instead of initiating a wave at one of the end of the fiber, we pace all tissue at the same time. When $\mathrm{I}_{\text {to }}$ is small, phase-1 repolarization is slow an then $\mathrm{I}_{\mathrm{CaL}}$ has the opportunity to develop and to produce a dome. For larger $\mathrm{I}_{\mathrm{to}}$, phase-1 is more pronounced and, if the membrane potential goes below the $\mathrm{I}_{\mathrm{CaL}}$ activation threshold, a domeless AP is produced. Then, depending on the value of $g_{\text {to }}$, the AP-dome may be lost in a part of tissue, resulting in a strong gradient of repolarization in the boundary between the two zones. This produces a large electrotonic current flow towards the area of high $g_{\text {to }}$, generating an $\mathrm{I}_{\mathrm{CaL}}$ induced action potential (slow upstroke) that propagates in the retrograde direction. If the $\mathrm{I}_{\mathrm{Na}^{+}}$has had enough time to 
recover, this slowly evolves to a $\mathrm{Na}^{+}$(rapid stroke) AP (Fig. 4), as the underlying $\mathrm{Na}^{+}$ reactivation amplifies the available $\mathrm{Na}^{+}$channels to be recruited for extending the propagating AP. It should be stressed that fast $\mathrm{I}_{\mathrm{Na}}$ depolarization does not occur at the boundary between the high and low $g_{\text {to }}$ zones, but at a given distance. This indicates that there must be a minimum tissue size with AP-dome loss in order to sustain reentry. In this work we do not address this problem, and simply define a threshold $(\mathrm{V}=-80 \mathrm{mV})$ to decide when repolarization takes place. If, after repolarization, the voltage again surpasses that threshold, and goes above $-20 \mathrm{mV}$ within the same stimulation period, we measure it as a reexcitation. This does not by itself indicate that sodium current has been triggered at that point, since this increase of voltage can be produced entirely by $\mathrm{I}_{\mathrm{CaL}}$, in which case it would rather be an EAD. Often, further down the tissue there is a point at which $\mathrm{I}_{\mathrm{Na}}$ induced depolarization occurs, as shown in Figure 4. Nevertheless, the question of how large the region without dome must be in order to have a $\mathrm{I}_{\mathrm{Na}^{+}}$induced reentry remains open.

Once a reexcitation takes place, the tissue conditions change. This results in a complicated dynamics where reexcitation occurs at some beats but not others (Fig. 2B). For that reason we define a probability based on the number of reexcitations observed in 200 beats, after the system has evolved enough to reach steady state in the ionic concentrations (25) (we take 500 beats). We consider various pairs of values of $g_{\text {to }}$ for the two epicardial regions, as well as different sodium current inactivation kinetics speed-ups. For all the values of $g_{\text {to }}$ considered, we observe a similar behavior. Even for normal sodium inactivation times, the loss of dome induced by heterogeneity in $\mathrm{I}_{\text {to }}$ is enough to produce reentry. The probability of reexcitation decreases as the stimulation period is decreased. In fact, for periods lower than $\mathrm{BCL}=700 \mathrm{~ms}$ we do not observe reexcitation (Fig. 5). This is in good agreement with the clinically observed fact that sudden cardiac death in patients with Brugada syndrome has a higher 
incidence during sleep when the cardiac rhythm is lower. As sodium inactivation kinetics are accelerated, the probability does not change monotonically, but there appear windows of vulnerability, where reexcitation is more likely to occur, separated by values of $\Gamma$ where phase-2 reentry is absent (Fig. 5). This is probably due to the contraposed effects of accelerated $\mathrm{h}$ gate closing kinetics. An important effect of this modification is to increase the percentage of domeless APs. However, from the simulations it is not clear that this alone is able to increase the probability of reexcitation (Fig. 6A), since the same effect shifts the potential for half inactivation towards more negative values (Fig. 1C), hindering depolarization. Since most mutations observed in Brugada syndrome are related to an increase in closed-state inactivation rate $(17,22,23)$, our results would suggest that this mutation alone is not enough to explain reentry in this disease. Another relevant effect of $\mathrm{I}_{\mathrm{Na}+}$ faster inactivation is the dramatic reduction in $\mathrm{CV}$ that is produced, since it is well known that slow conduction is an important component of the reentry substrate.

Thus, the loss of AP dome in a region of epicardium does not necessarily imply that reexcitation will occur. For instance, if $g_{\text {to }}$ in that region is too large, the AP-dome is always lost but diffusion is not able to initiate the rise of $\mathrm{I}_{\mathrm{CaL}}$ that may induce reexcitation. The most dangerous situation occurs when the combination of factors ( $\mathrm{I}_{\text {to }}$ density, sodium kinetics, etc) favors a critical state where the loss of AP-dome in a region of tissue depends very sensitively on dynamic factors. Even in this case where conditions are suitable for reexcitation, the region where the AP loses the dome must be large enough so that, as the $\mathrm{I}_{\mathrm{CaL}}$ induced pulse propagates, it is able to encounter already excitable tissue. If this region is small, instead of a reexcitation, the increase in transmembrane voltage induced by neighboring regions would result in an early after depolarization. 
We must point out that this mechanism for reexcitation is based entirely on regional differences within the epicardium. In this model transmural dispersion of repolarization does not play a role in reentry, the endocardium being a merely passive layer. This is supported by recent results obtained in experiments in a canine Brugada model, where variations in the duration of action potential occurred in the epicardium, but not in the mid- and endocardium $(27,28)$. Furthermore, the observed change in AP was heterogeneous in the epicardium, resulting in reentry in this layer, but not transmurally.

Some drugs such as the isoproterenol have apparently been successful in suppressing VF recurrences and electrical storms related with Brugada Syndrome (29,30,31). Isoproterenol produces beta-adrenergic stimulation, increasing the cardiac rhythm, the vagal tone, and enhancing $\mathrm{I}_{\mathrm{CaL}}$. A rise of heart rate decreases the probability of reexcitations, as shown in Fig. 5A. The increase of $\mathrm{I}_{\mathrm{CaL}}$ restores the dome of epicardial action potentials, thereby reducing the heterogeneity that is the basis of the reentry. Clinically, it has been observed that isoproterenol eliminates the ST-elevation, but only if the administered dose is above a certain value (31). This agrees with our results in Fig. 7, where there is a threshold value of $\mathrm{I}_{\mathrm{CaL}}$ above which reexcitation disappears. Our results suggest that the dose must be high enough to recover the AP-dome in all tissue, otherwise its effect would be pro-arrhythmic. Given the importance that heterogeneity of $\mathrm{I}_{\mathrm{to}}$ plays in the genesis of reentry in our model, drugs capable of reducing the $\mathrm{I}_{\text {to }}$ ( such as $\mathrm{I}_{\text {to }}$ blockers) seem to be good candidates for treating Brugada Syndrome (19).

\section{CONCLUSION}


Our results confirm that dispersion of repolarization may result in reentry, in agreement with the 'repolarization disorder hypothesis'. Considering a Brugada syndrome ECG pattern due exclusively to a mutation in $\mathrm{I}_{\mathrm{Na}}$ channel functionality, the loss of dome occurs for values of the transient outward current strength $g_{\text {to }}$ which are probably larger than those present in human epicardium (32). However, in cases where there are also mutations causing loss of function of $\mathrm{I}_{\mathrm{CaL}}(7)$, reentry could be obtained for lower values of $g_{\text {to }}$.

\section{Limitations}

There are important limitations to this study. First, we have considered both a one dimensional fiber with an idealized distribution of $\mathrm{I}_{\text {to }}$ current densities and a two dimensional patch of epicardial tissue, without including fiber anisotropy. Clearly, to obtain a better description of the mechanisms of reentry in the right ventricle, three dimensional simulations with transmural propagation and including endo-, mid-, and epicardium cells are necessary. Nevertheless, if propagation on Purkinje fibers is very fast compared with transmural propagation, the epicardial tissue will be stimulated almost at once, as in our simulations.

The model that we use does not describe any specific mutation related with Brugada syndrome. This could be achieved by considering a more elaborate description of the sodium kinetics, using a Markov model, as has been described in the literature (33). Since we are using a model for guinea pig, it is difficult to evaluate the relevance of our results in a human heart. Even so, we believe that the qualitative trends will be similar.

Finally, although the Luo-Rudy model is physiologically based, it is not a complete model. In particular, a better formulation of $\mathrm{Ca}^{2+}$ dynamics should be included. This is an important 
point, since the calcium current $\mathrm{I}_{\mathrm{CaL}}$ plays a relevant role in the mechanism responsible for reexcitation.

\section{SOURCES OF FUNDING}

This study was supported by Ministerio de Educación y Ciencia (Spain), under projects FIS2005-06912-C02-01, FIS2008-06335-C02-01 and FIS2006-11452-C03-02. BE also wishes to acknowledge financial support from the Ministerio de Ciencia y Tecnología (Spain) under the Ramón y Cajal program.

\section{DISCLOSURES}

None 


\section{BIBLIOGRAPHY}

1. Antzelevitch C. Heterogeneity and cardiac arrhythmias: an overview. Heart Rhythm 4: 964-972, 2007.

2. Xie F, Qu Z, Garfinkel A, Weiss JN. Electrophysiological heterogeneity and stability of reeentry in simulted cardiac tissue. Am J Physiol Heart Circ Physiol 280: H535-545, 2001.

3. Brugada P, Brugada J. Right bundle block, persistent ST segment elevation and cardiac death: A distinct clinical electrocardiographic syndrome-a multicenter report. J Am Coll Cardiol 20: 13911396, 1992.

4. Antzelevitch C, Brugada P, Borggrefe M, Brugada J, Brugada R, Corrado D, Gussak I, LeMarec H, Nademanee K, Perez Riera AR, Shimizu W, Schulze-Bahr E, Tan H, Wilde A. Brugada syndrome: Report of the second consensus conference. Heart Rhythm 2: 429-440, 2005.

5. Study group on molecular basis of arrhythmias. Inherited Arrhythmias Database http://www.fsm.it/cardmoc/

6. Chen Q, Kirsch GE, Zhang D, Brugada R, Brugada J, Brugada P, Potenza D, Moya A, Borggrefe M, Breithardt G, Ortiz-Lopez R, Wang Z, Antzelevitch C, O'Brien RE, Schulze-Bahr E, Keating MT, Towbin JA, Wang Q. Genetic basis and molecular mechanisms for idiopathic ventricular fibrillation. Nature 392: 293-296, 1998.

7. Antzelevitch C, Pollevick GD, Cordeiro JM, Casis O, Sanguinetti MC, Aizawa Y, Guerchicoff A, Pfeiffer R, Oliva A, Wollnik B, Gelber P, Bonaros EP, Burashnikov E, Wu Y, Sargent JD, Schickel S, Oberheiden R, Bhatia A, Hsu L-F, Haïssaguerre M, Schimpf R, Borggrefe M, Wolpert C. Loss-of-function mutations in the cardiac calcium channel underlie a new clinical entity characterized by ST-Segment elevation, short QT intervals, and sudden cardiac death. Circulation 115: 442-449, 2007.

8. Wilde AA, Antzelevitch C, Borggrefe M, Brugada J, Brugada R, Brugada P, Corrado D, Hauer RNW, Kass RS, Nademanee K, Priori SG, Towbin JA. Proposed diagnostic criteria for the Brugada syndrome: consensus report. Circulation 106: 2514-2519, 2002.

9. Antzelevitch C, Brugada P, Brugada J, Brugada R. The Brugada syndrome: From bench to bedside. Oxford, UK: Blackwell Futura, 2005. 
10. Antzelevitch C. Role of spatial dispersion of repolarization in inherited and acquired sudden cardiac death syndromes. Am J Physiol Heart Circ Physiol 293: H2024-H2038, 2007.

11. Di Diego JM, Antzelevitch C. High $\left[\mathrm{Ca}^{2+}\right]_{0}$-induced electrical heterogeneity and extrasystolic activity in isolated canine ventricular epicardium: Phase 2 reentry. Circulation 89: 1839-1850, 1994.

12. Brahmajothi MV, Campbell DL, Rasmusson RL, Morales MJ, Trimmer JS, Nerbonne JM, Harold CS. Distinct transient outward potassium current $\left(\mathrm{I}_{\text {to }}\right)$ phenotypes and distribution of fastinactivating potassium channel alpha subunits in ferret left ventricular myocytes. J Gen Physiol 113: 581-600, 1999.

13. Lukas A, Antzelevitch C. Phase 2 reentry as a mechanism of initiation of circus movement reentry in canine epicardium exposed to simulated ischemia. Cardiovasc Res 32: 593-603, 1996.

14. Hopenfeld B. Mechanism for action potential alternans: The interplay between L-type calcium current and transient outward current. Heart Rhythm 3: 345-352, 2006.

15. Miyoshi S, Mitamura H, Fujikura K, Fukuda Y, Tanimoto K, Hagiwara Y, Makoto I, Satoshi O. A mathematical model of phase 2 reentry: Role of L-type Ca current. Am. J Physiol Heart Circ Physiol 284: H1285- H1294, 2003.

16. Miyoshi S, Mitamura H, Fukuda Y, Tanimoto K, Hagiwara Y, Kanki H, Seiji T, Mitsushige M, Toshihisa M, Satoshi O. Link between SCN5A mutation and the Brugada syndrome ECG phenotype. Circ J 69: 567-575, 2005.

17. Petitprez S, Jespersen T, Pruvot E, Keller DI, Corbaz C, Schläpfer J, Abriel H, Kucera JP. Analyses of a novel SCN5A mutation (C1850S): conduction vs. repolarization disorder hypotheses in the Brugada syndrome. Cardiovasc Res 78: 494-504, 2008.

18. Luo CH and Rudy Y. A dynamic model of the cardiac ventricular action potential. I. Simulations of ionic currents and concentration changes. Circ Res 74: 1071-1096, 1994.

19. Dumaine R, Towbin JA, Brugada P, Vatta M, Nesterenko DW, Nesterenko VV. Ionic mechanisms responsible for the electrocardiographic phenotype of the Brugada syndrome are temperature dependent. Circ Res 85: 803-809, 1999. 
20. Grant AO, Carboni MP, Neplioueva V, Starmer CF, Memmi M, Napolitano C, Priori S. Long QT syndrome, Brugada syndrome, and conduction system disease are linked to a single sodium channel mutation. J Clin Invest 110: 1201-1209 (2002).

21. Casini S, Tan HL, Bhuiyan ZA, Bezzina CR, Barnett P, Cerbai E, Mugelli A, Wilde AAM, Veldkamp MW. Characterization of a novel SCN5A mutation associated with Brugada syndrome reveals involvement of DIIIS4-S5 linker in slow inactivation. Cardiovasc Res 76: 418-429 (2007).

22. Zhang Z-S, Tranquillo J, Neplioueva V, Bursac N, Grand AO. Sodium channel kinetic changes that produce Brugada syndrome or progressive cardiac conduction system disease. Am J Physiol Heart Cir Physiol 292: H399-H407 (2007)

23. Makita N, Shirai N, Wang DW, Sasaki K, George AL, Kanno M, Kitabatake A. Cardiac Na+ channel dysfunction in Brugada syndrome is aggravated by $\beta 1$ - subunit. Circulation 101: 54-60 (2000)

24. http://rudylab.wustl.edu/index.html

25. Hund TJ, and Rudy Y. Determinants of excitability in cardiac myocytes: Mechanistic investigation of memory effect. Biophys J 79: 3095-3104, 2000.

26. Shajahan TK, Sinha S, and Pandit, R. Spiral-wave dynamics depend sensitively on inhomogeneities in mathematical models of ventricular tissue. Physical Review E 75: 011929, 2007.

27. Aiba T, Shimizu W, Hidaka I, Uemura K, Noda T, Zheng C, Kamiya A, Inagaki M, Sugimachi M, Sunagawa K. Cellular basis for trigger and maintenance of ventricular fibrillation in the Brugada syndrome model - High-resolution optical mapping study. J Am Coll Cardiol 47: 2074-2085, 2006.

28. Morita H, Zipes DP, Lopshire J, Morita ST, Wu J. T wave alternans in an in vitro canine tissue model of Brugada syndrome. Am J Physiol Heart Circ Physiol 291: H421-H428, 2006.

29. Márquez MF, Salica G, Hermosillo AG, Pastelin G, Gómez-Flores J, Nava S, Cárdenas M. Ionic basis of pharmacological therapy in Brugada syndrome, J Cardiovasc Electrophysiol 18: 234-240, 2007. 
30. Maury P, Hocini M, and Haïssaguerre M. Electrical storms in Brugada syndrome: Review of pharmacologic and ablative therapeutic options. Indian Pacing Electrophysiol J 5: 25-34, 2005.

31. Tanaka H, Kinoshita O, Uchikawa S, Kasai H, Nakamura M, Izawa A, Yokoseki O, Kitabayashi H, Takahashi W, Yazaki Y, Watanabe N, Imamura H, Kubo K. Successful prevention of recurrent ventricular fibrillation by intravenous isoproterenol in a patient with Brugada syndrome. PACE 24: 1293-1294, 2001.

32. Li GR, Feng J, Yue L, Carrier M. Transmural heterogeneity of action potentials and Ito1 in myocytes isolated from the human right ventricle. Am J Physiol Heart Circ Physiol 275:H369H377, 1998.

33. Clancy CE, Rudy Y. Na+ channel mutation that causes both Brugada and long-QT syndrome phenotypes: a simulation study of mechanism. Circulation 105: 1208-1213, 2002. 


\section{FIGURES}

Fig. 1. Modification in the steady state $\mathrm{h}_{\mathrm{inf}}$ and relaxation time $\tau_{\mathrm{h}}$ of the $\mathrm{I}_{\mathrm{Na}+}$ inactivation gate $\mathrm{h}$, due to a change in the rate constants $\alpha_{\mathrm{h}}(V)(\mathrm{A}$ and $\mathrm{B})$ and $\beta_{\mathrm{h}}(V)(\mathrm{C}$ and $\mathrm{D})$ by a factor up to $10\left(\Gamma_{\alpha}, \Gamma_{\beta}=1-10\right.$, see Eq. 1). The arrow indicates the effect of increasing $\Gamma_{\alpha}$ or $\Gamma_{\beta}$.

Fig. 2. Simulations in a cable of length $4 \mathrm{~cm}$. In (A) and (B) the transmembrane voltage vs. time is shown in the first and last 10 seconds of the simulation, for $g_{\text {to }}=1.1 \mathrm{mS} / \mu \mathrm{F}$ and $\mathrm{I}_{\mathrm{Na}+}$ inactivation accelerated by a factor $\Gamma=3$. We show the variation of APD (C and D), the percentage of domeless APs (E and F), and $\mathrm{CV}(\mathrm{H}$ and $\mathrm{G})$ under a change in $g_{\text {to }}$ and $\Gamma$. In $(\mathrm{C})$ and (D) the symbols correspond to the average value of 100 APDs, with the bars indicating the standard deviation. For $g_{\text {to }}=0.8 \mathrm{mS} / \mu \mathrm{F}$ the APD slightly increases with $\Gamma$, without ever losing the dome, while for $g_{\mathrm{to}}=1.3 \mathrm{mS} / \mu \mathrm{F}(\mathrm{C})$ an alternation between long and short APDs is observed, hence the two clusters of points corresponding to the average values for each case.

Fig. 3. Propagation of AP in a cable of length $3 \mathrm{~cm}$, with a jump of $I_{\text {to }}$ conductance. We show typical action potentials for $\Gamma=3$ at positions $x=\mathrm{L} / 4(\mathrm{~A})$ and $x=3 \mathrm{~L} / 4(\mathrm{~B})$, in the case where the jump is from $g_{\text {to }}=1.1 \mathrm{mS} / \mu \mathrm{F}$ to $g_{\text {to }}=1.3 \mathrm{mS} / \mu \mathrm{F}$. In the region with high $g_{\text {to }}$ the AP is not unique, but alternates between states with and without dome (B). The space-time evolution of the transmembrane potential at different points in the cable is shown in (C)-(F). To help visualization we displace the value of the potential by $10 \mathrm{mV}$ for each consecutive point along the cable, separated by $2 \mathrm{~mm}$. In (C) and (D) the fiber is stimulated from the region of high $g_{\text {to }}$ (in this case the high value of $g_{\text {to }}$ is $1.5 \mathrm{mS} / \mu \mathrm{F}$ ), with a pacing period of $\mathrm{BCL}=1000$ ms. Reexcitation is produced in some beats $(\mathrm{D}$, indicated by the arrow), but not in others $(\mathrm{C})$. The same protocol is followed in $(\mathrm{E})$ and $(\mathrm{F})$, but with the stimulus given on the region of low $g_{\text {to }}$ (the discontinuity in $\mathrm{g}_{\text {to }}$ is placed at $\mathrm{x}=\mathrm{L} / 4$ and). The bold line corresponds to the space-time evolution of the voltage at the point of the discontinuity.

Fig. 4. Distribution along the cable of the transmembrane potential, inactivation gates $\mathrm{h}$ and $\mathrm{j}$ of sodium current $\mathrm{I}_{\mathrm{Na}}$, and calcium current $\mathrm{I}_{\mathrm{CaL}}$, corresponding to Fig. $3 \mathrm{D}$, at different times. The time difference between two consecutive frames is $\mathrm{t}=10 \mathrm{~ms}$. In the region of higher $g_{\text {to }}$, 
the $\mathrm{AP}$ is short due to the lack of calcium current $\mathrm{I}_{\mathrm{CaL}}$. As the pulse propagates into the region with smaller value of $g_{\text {to }}(\mathrm{A}-\mathrm{C})$, the dome is recovered (D-E), increasing the value of the voltage in phase 2 . The longer APD in this region creates a spatial dispersion of repolarization, in such a way that voltage diffuses back into the region of large $g_{\text {to }}(\mathrm{F}-\mathrm{H})$. If, by that time, the tissue is already excitable (the $\mathrm{I}_{\mathrm{Na}+}$ inactivation gates have reopened), a retrograde pulse is generated (I).

Fig. 5. Percentage of reexcitations: (A) as a function of stimulation period BCL, for several values of the sodium current inactivation channel speed-up $\Gamma$; (B) as a function of $\mathrm{I}_{\mathrm{Na}+}$ inactivation speed-up $\Gamma$, for several values of the pacing period BCL. The values of $I_{t o}$ conductance selected in the two halves of the fiber are $g_{\mathrm{to}}=1.1 \mathrm{mS} / \mu \mathrm{F}$ and $g_{\mathrm{to}}=1.3 \mathrm{mS} / \mu \mathrm{F}$. (C) Percentage of reexcitations as a function of $\Gamma$, for several values of the transient outward current conductance $g_{\text {to }}$ in the two parts of the fiber, and a pacing period $\mathrm{BCL}=1000 \mathrm{~ms}$.

Fig. 6. Percentage of reexcitations as a function of (A) $\Gamma_{\alpha}$, for fixed $\Gamma_{\beta}=1$ and 4; and (B) $\Gamma_{\beta}$, for $\Gamma_{\alpha}=1$ and 4 . The values of $I_{\text {to }}$ conductance selected in the two halves of the fiber are $g_{\text {to }}=1.1 \mathrm{mS} / \mu \mathrm{F}$ and $g_{\text {to }}=1.3 \mathrm{mS} / \mu \mathrm{F}$.

Fig. 7. Percentage of reexcitations as a function of calcium current strength, for several values of $\Gamma$. The change in the calcium current is obtained multiplying $\mathrm{I}_{\mathrm{CaL}}$ in the model by a given factor, represented in the horizontal axis as a percentage. The values of $\mathrm{I}_{\text {to }}$ conductance selected in the two halves of the fiber are $g_{\mathrm{to}}=1.1 \mathrm{mS} / \mu \mathrm{F}$ and $g_{\mathrm{to}}=1.3 \mathrm{mS} / \mu \mathrm{F}$.

Fig. 8. Creation of a spiral wave in a $4 \mathrm{~cm} \times 4 \mathrm{~cm}$ sheet of epicardial tissue, with heterogeneous distribution of $\mathrm{I}_{\text {to }}$ conductance, and sodium current inactivation speed-up $\Gamma=4$. In the upper panels we show the distribution of the transmembrane potential $\mathrm{V}_{\mathrm{m}}$, with lighter density representing lower potential. All epicardial tissue is stimulated simultaneously with a period of $\mathrm{BCL}=1000 \mathrm{~ms}$. In all the tissue the $\mathrm{I}_{\mathrm{to}}$ conductance is $g_{\mathrm{to}}=1.3 \mathrm{mS} / \mu \mathrm{F}$, except in a triangular region (shown by dashed lines in the first picture) where it takes the value $g_{\text {to }}=1.1$ $\mathrm{mS} / \mu \mathrm{F}$. The time interval between frames is $50 \mathrm{~ms}$, except for the last illustration, which shows a typical snapshot some time after the first spiral has broken up. In the lower panels we show the time evolution of the transmembrane potential $\mathrm{V}_{\mathrm{m}}$ at four different sites of tissue. The arrows correspond to the beat shown in the upper panels, indicating the reexcitation at 
the points $b, c$ and $d$, and the appearance of reentry with the reexcitation of point $a$, that finally results in block at the point $b$. A couple of beats later, reentry occurs again, resulting in six extra beats. 

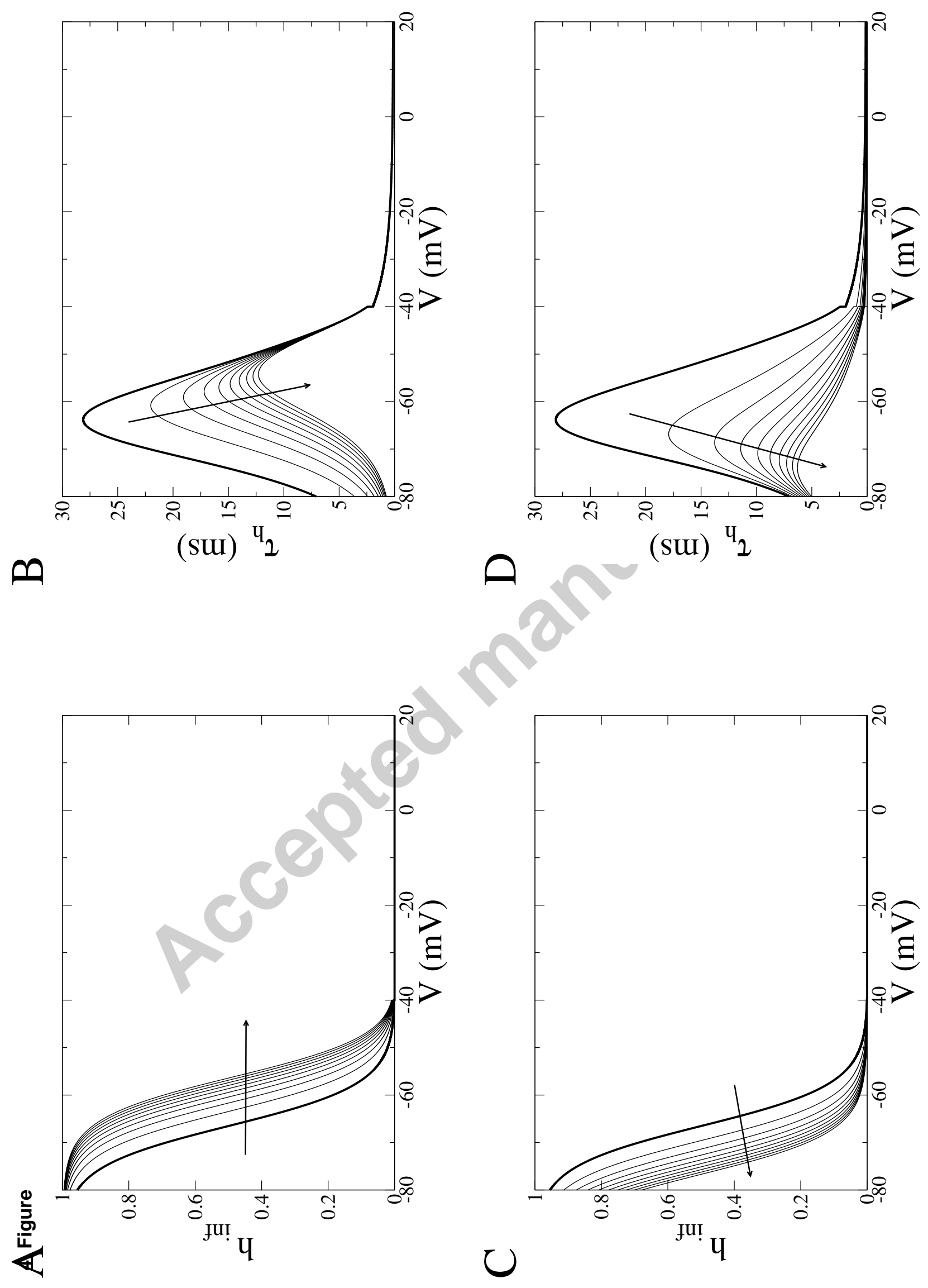


\section{ACCEPTED MANUSCRIPT}

4. Aigure

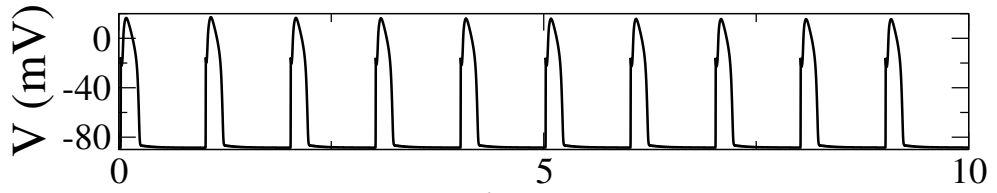

C

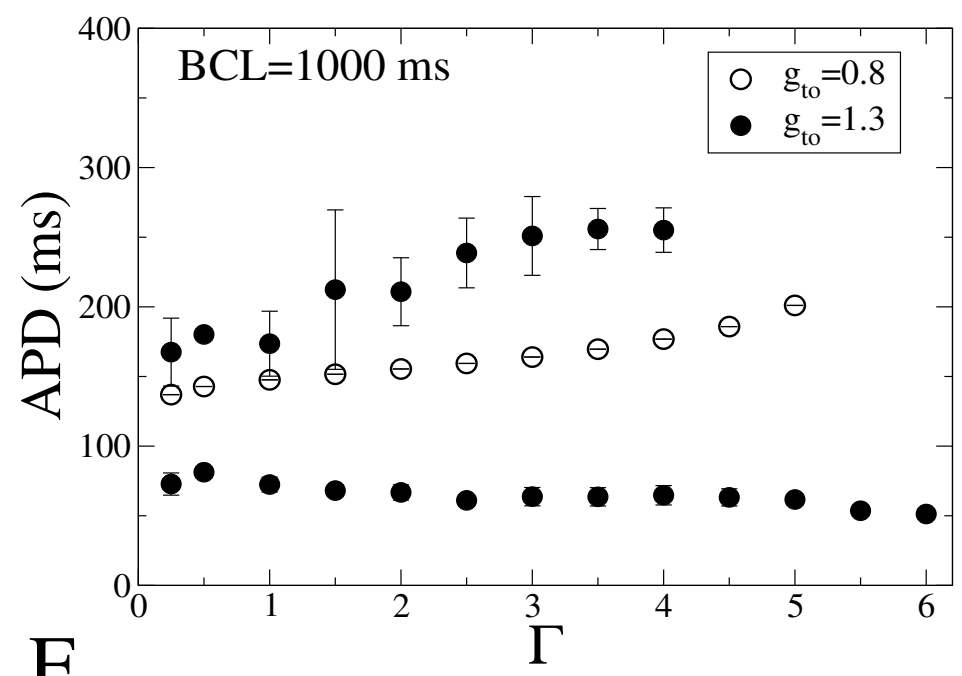

$\mathrm{E}$ time (s)

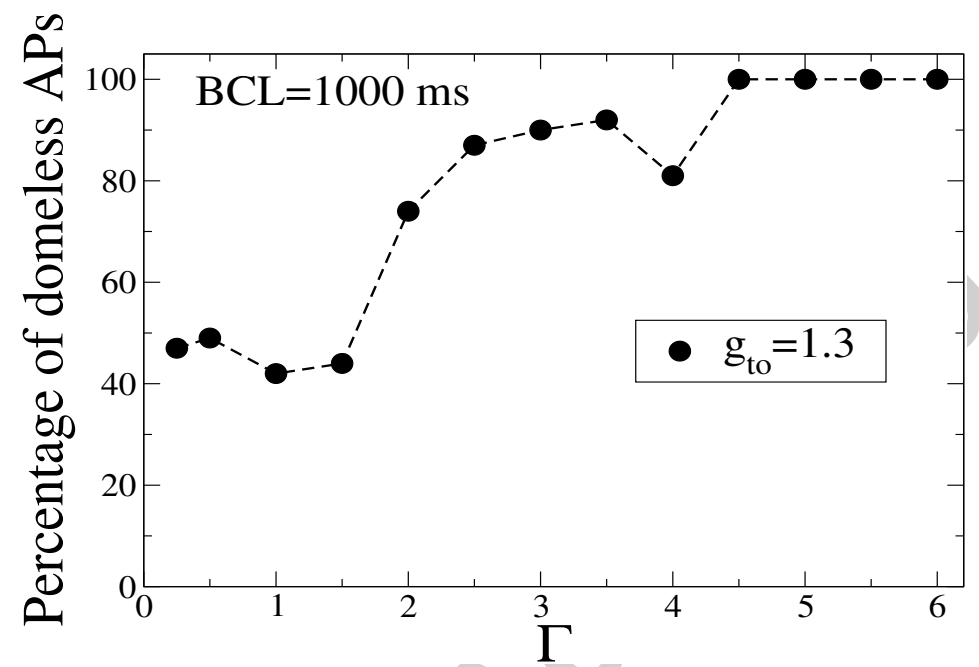

G

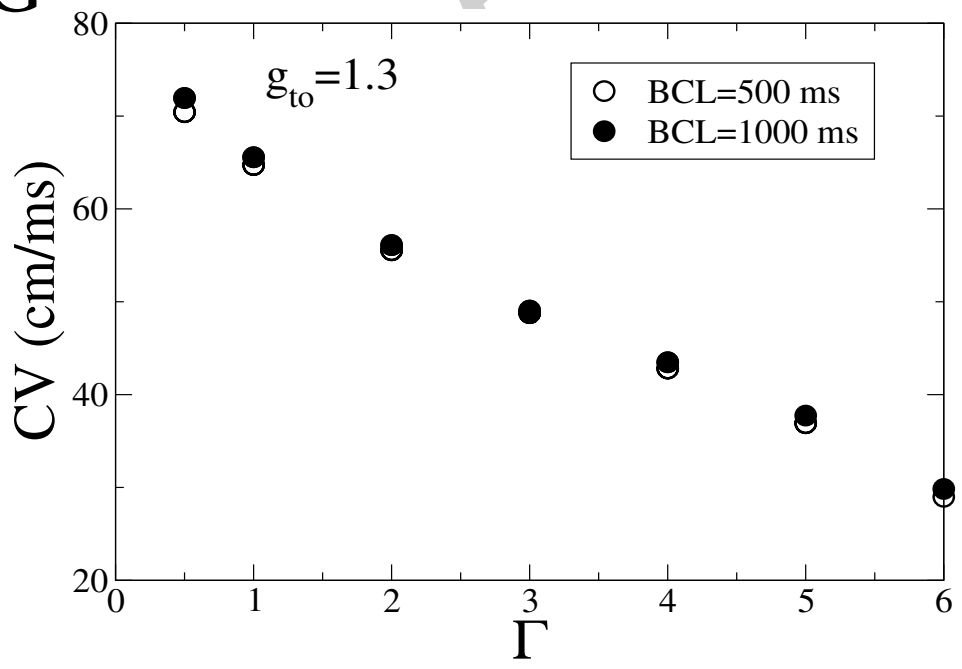

B
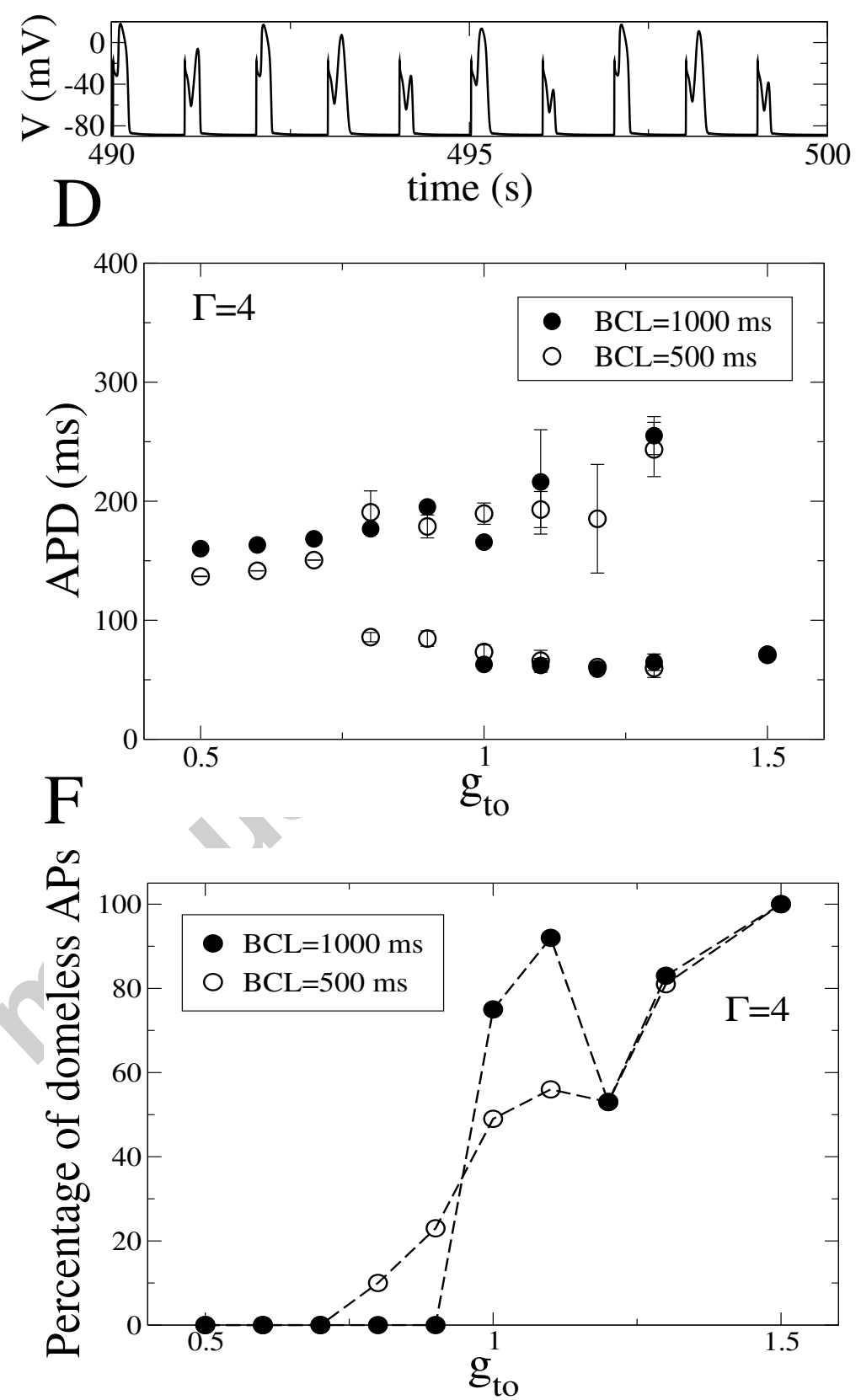

$\mathrm{H}$

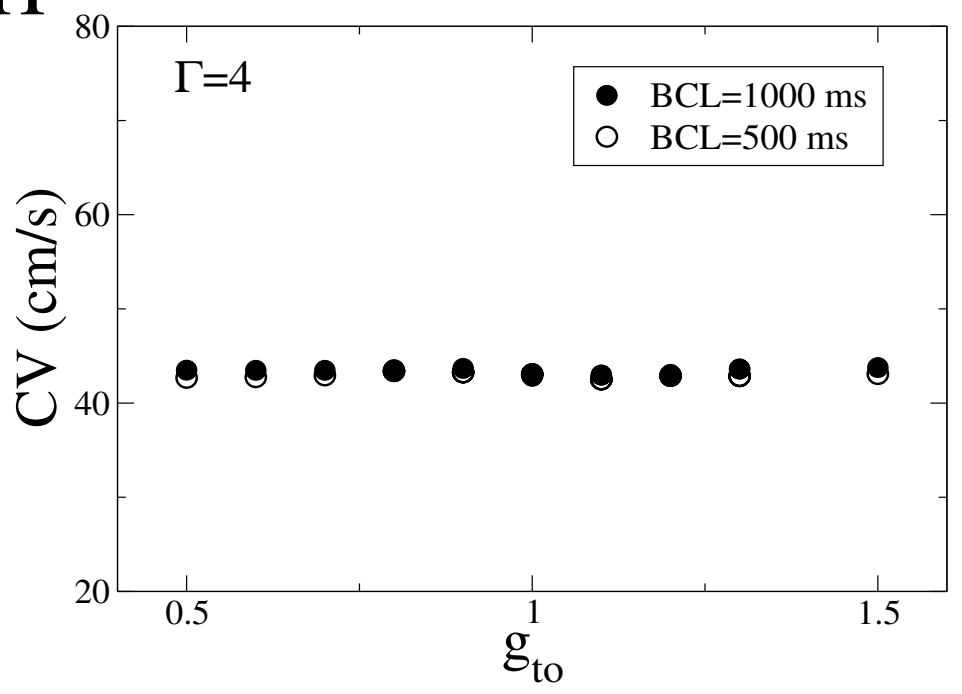


A

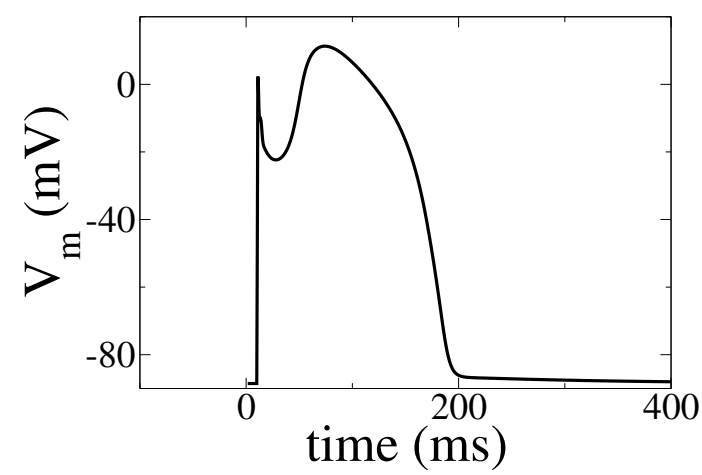

B

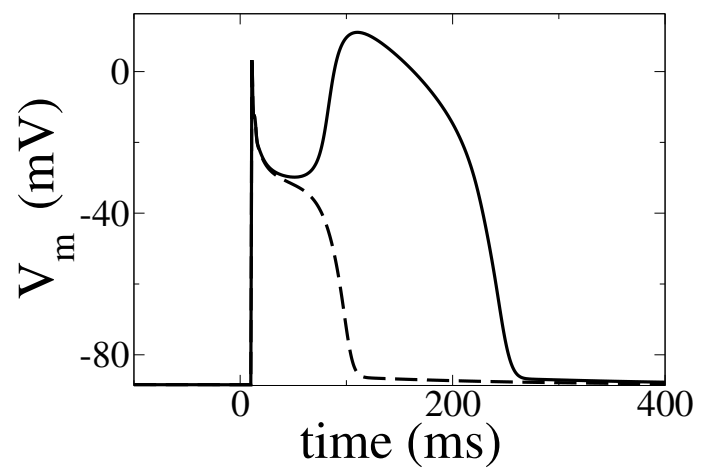

\section{$g_{\text {to }}=1.1$}

$$
g_{\text {to }}=1.3
$$

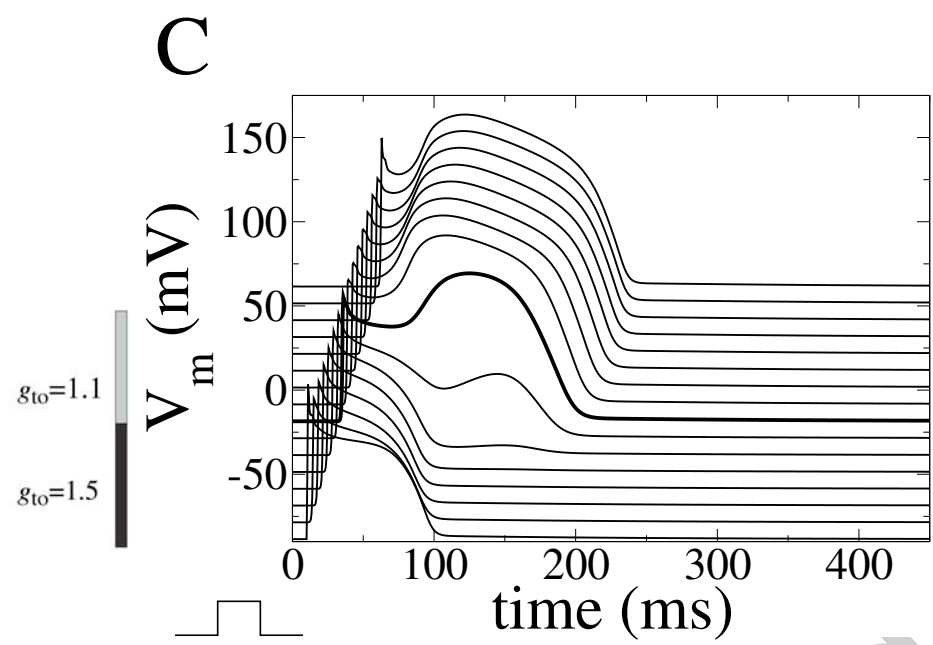

D
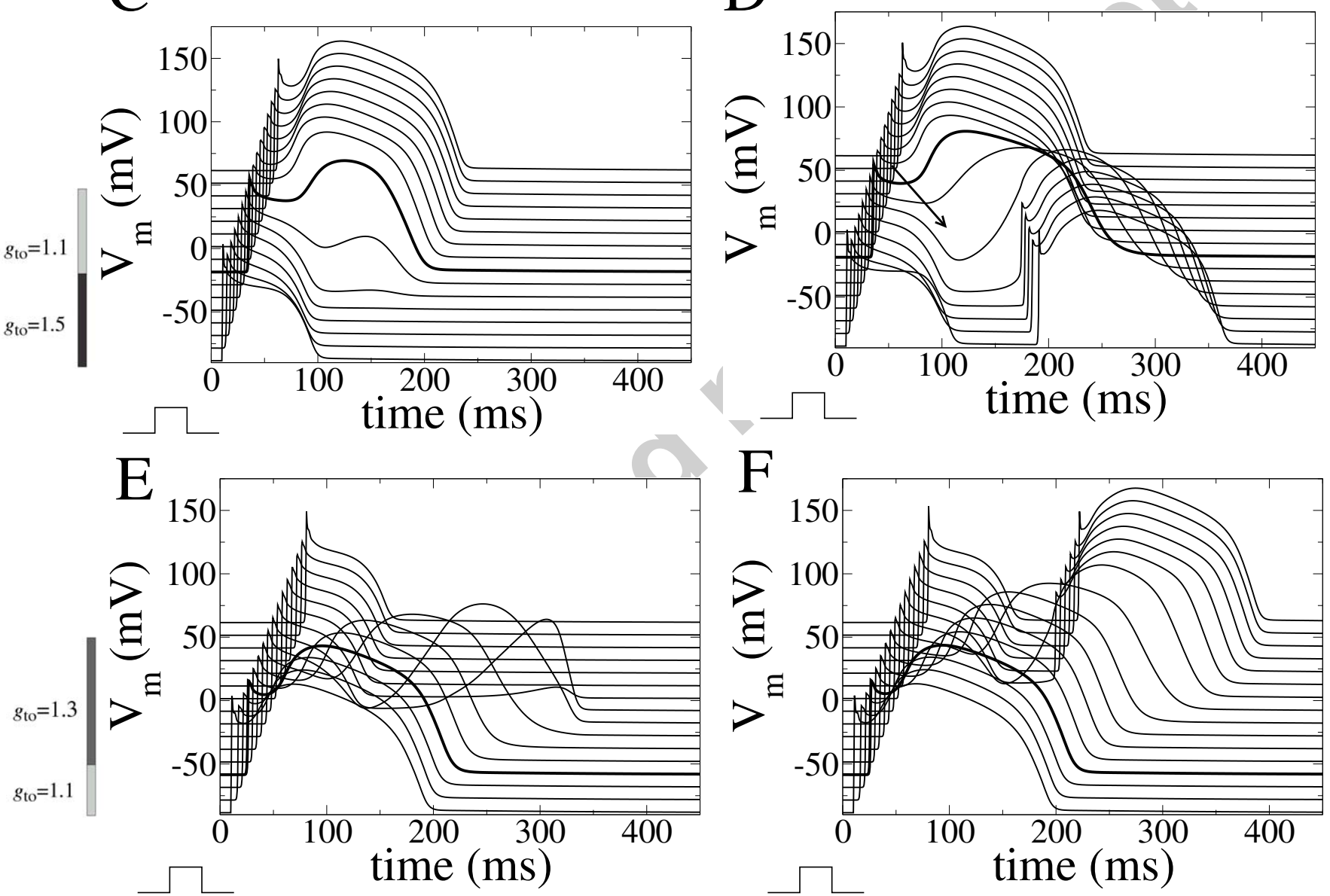


\section{ACCEPTED MANUSCRIPT}

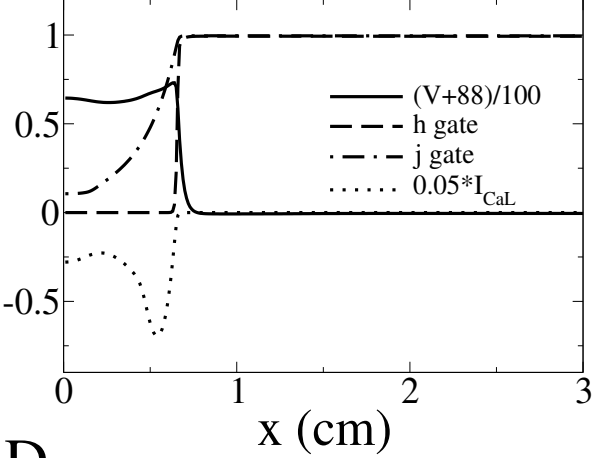

$\mathrm{D}$

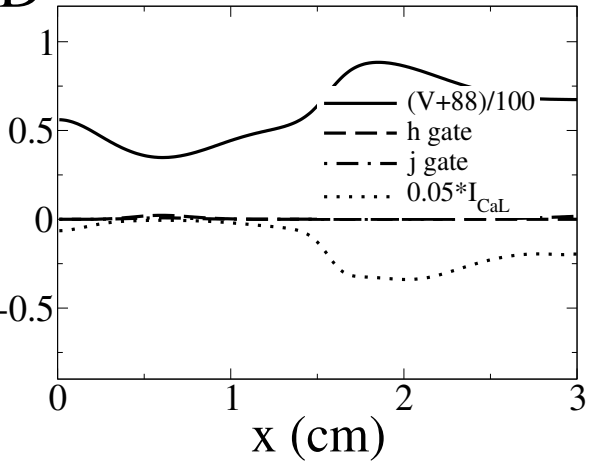

G

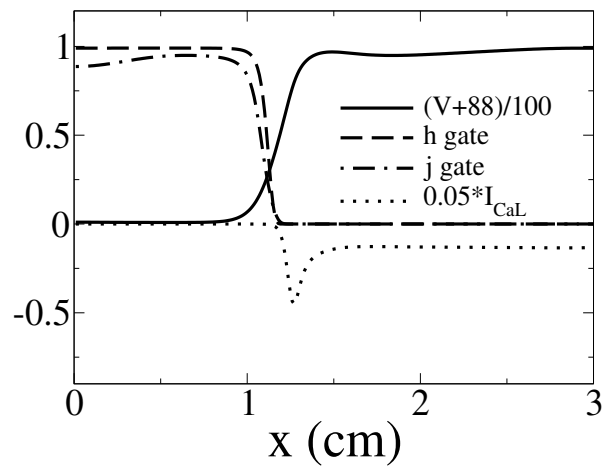

$g_{\mathrm{to}}=1.5 \quad g_{\mathrm{to}}=1.1$
B

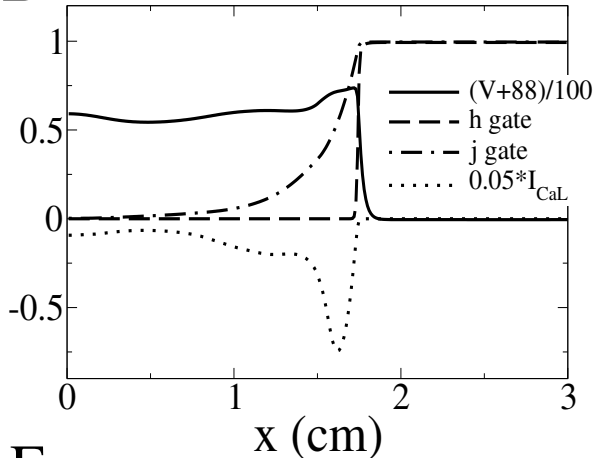

E

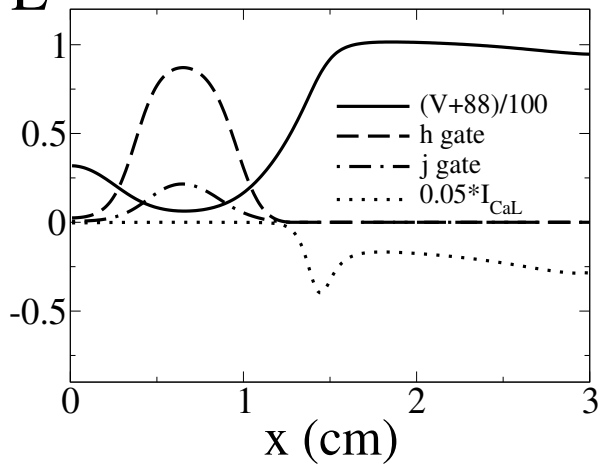

$\mathrm{H}$

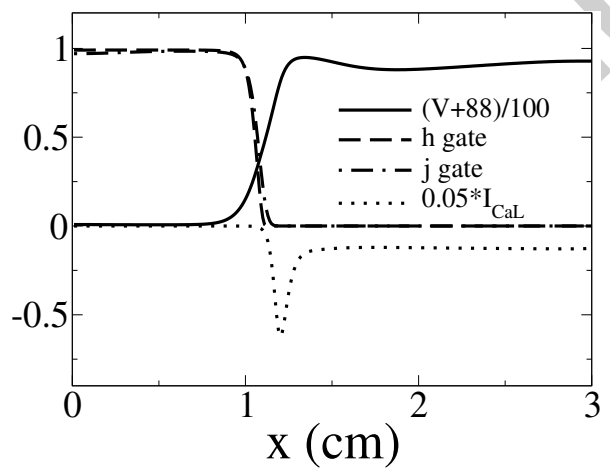

$g_{\mathrm{to}}=1.5 \quad g_{\mathrm{to}}=1.1$
C

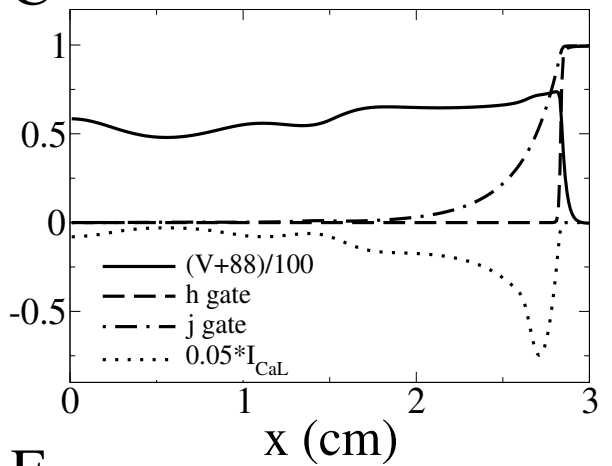

F

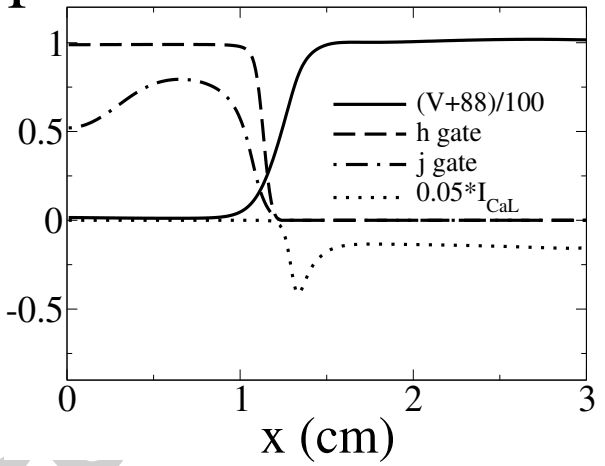

I

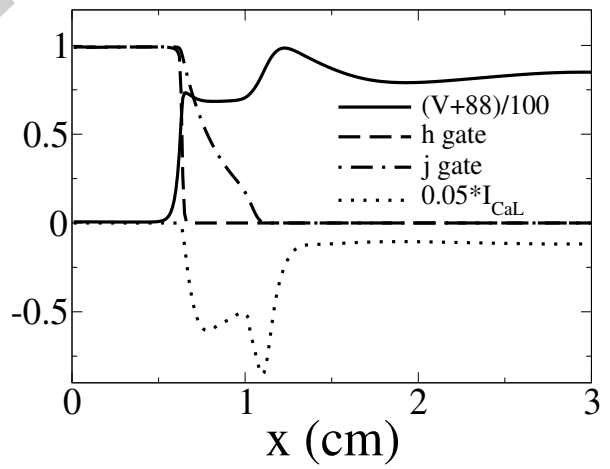

$g_{\mathrm{to}}=1.5 \quad g_{\mathrm{to}}=1.1$ 

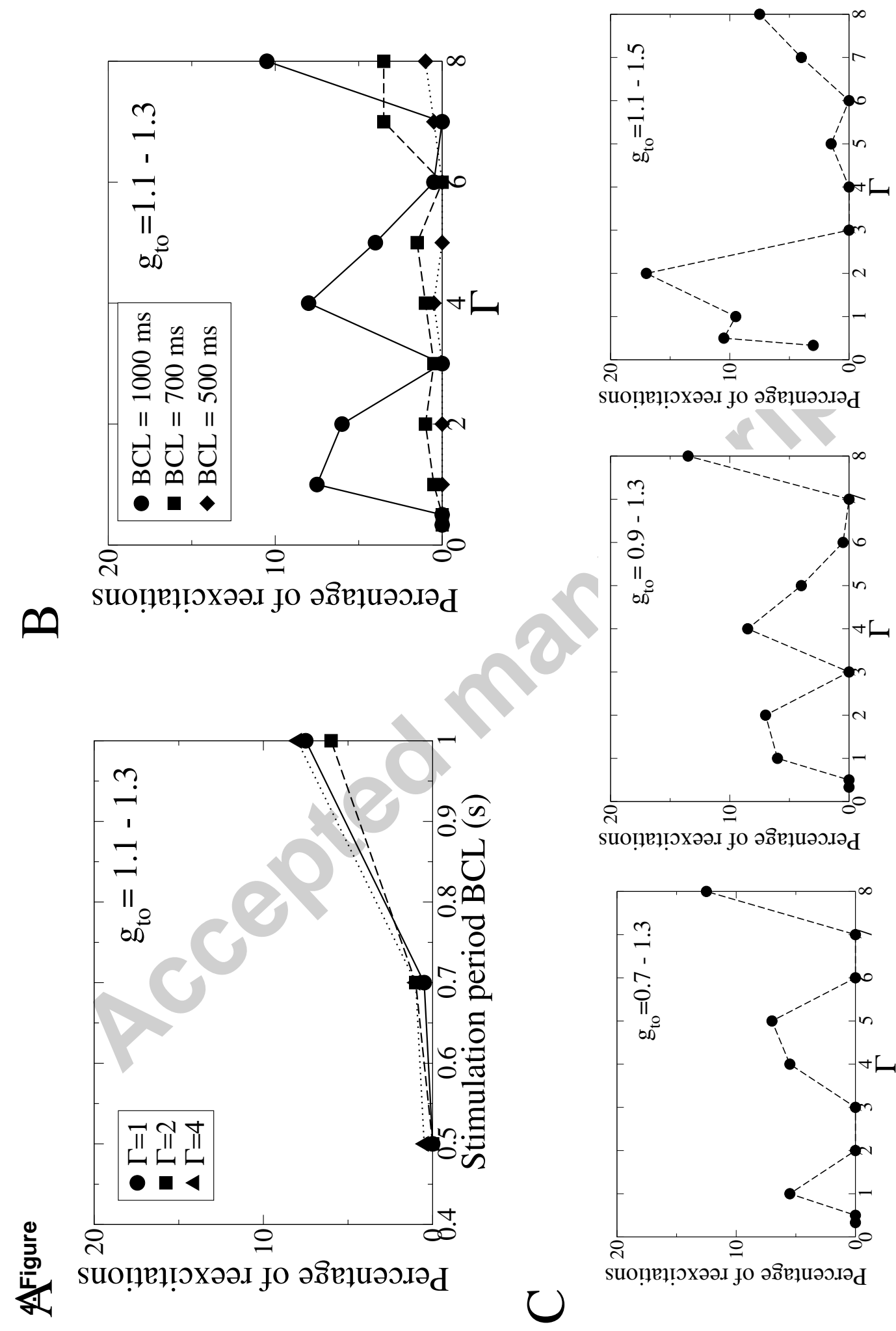

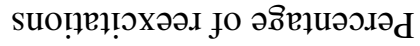

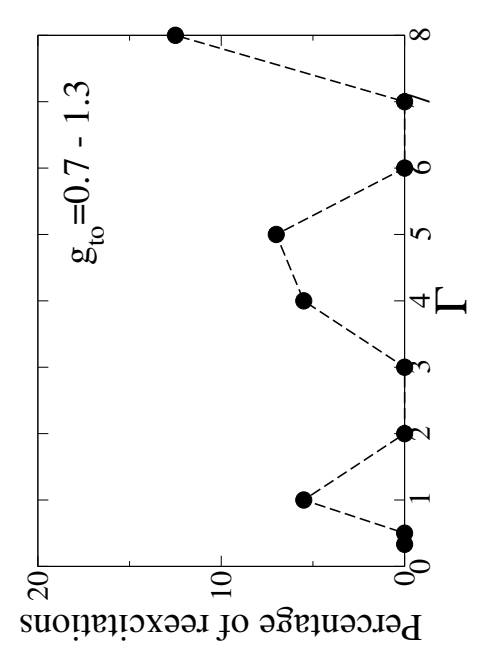




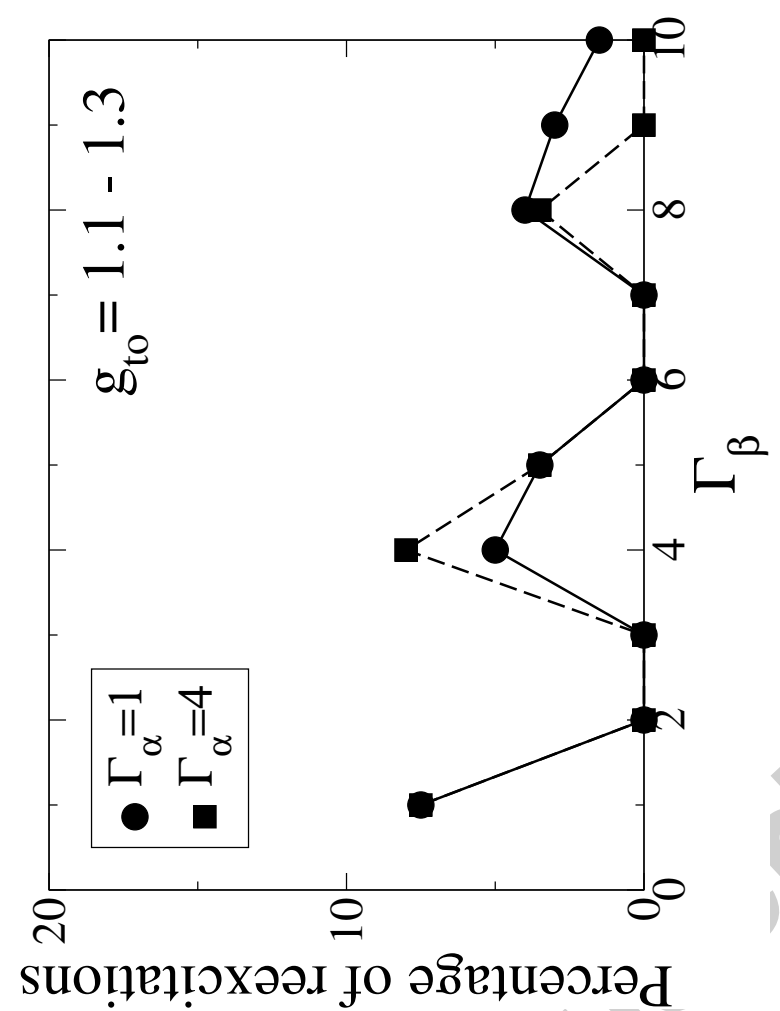

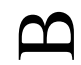

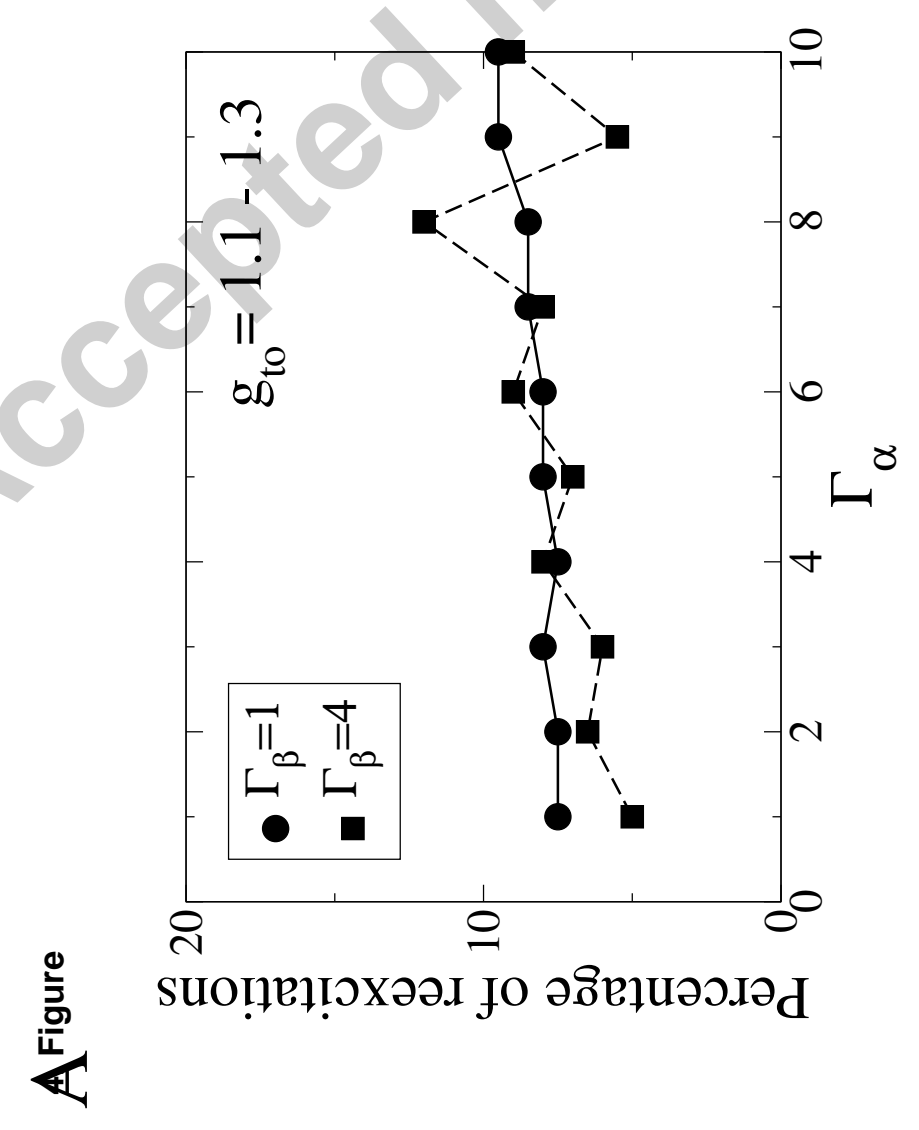




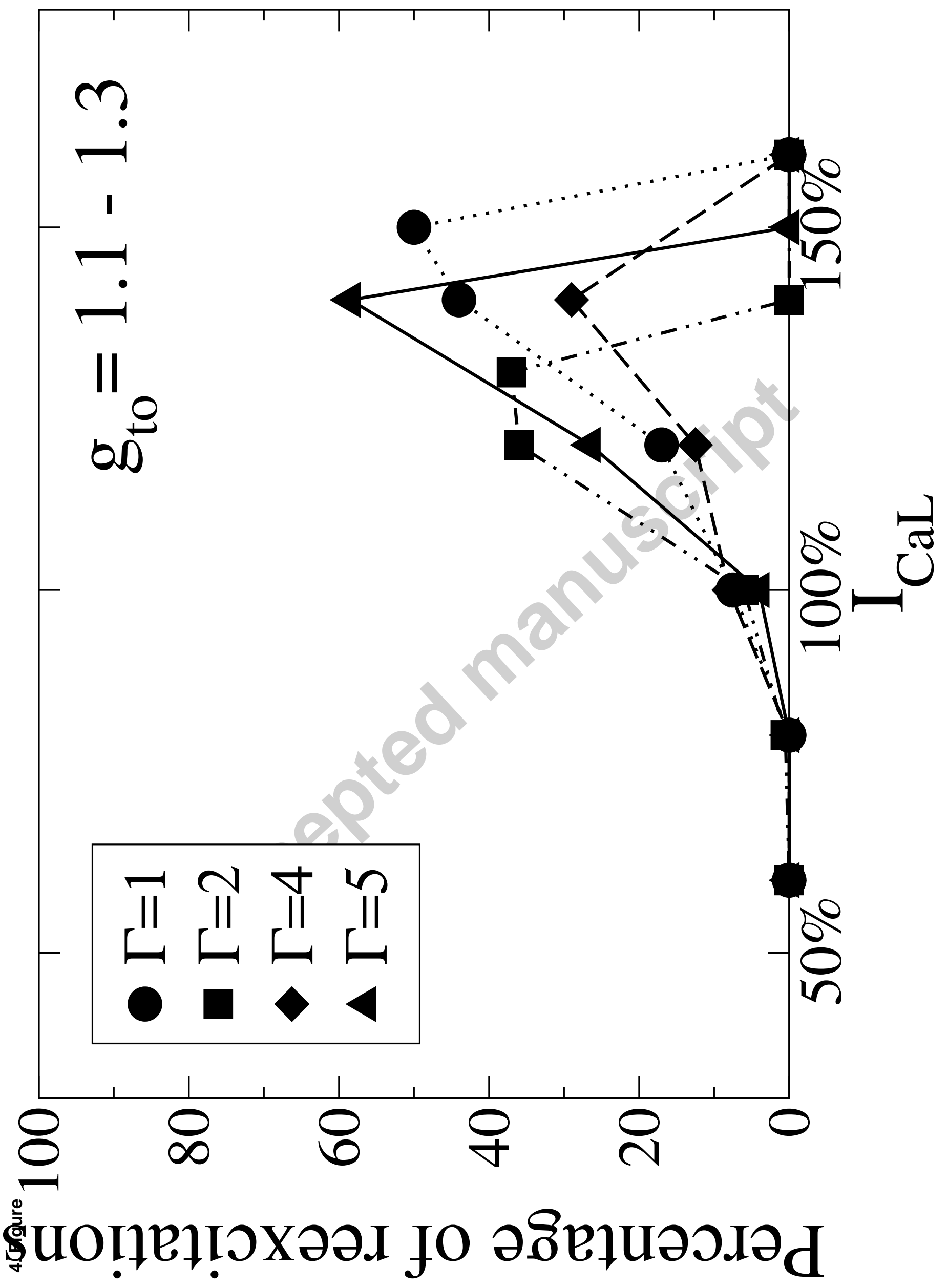



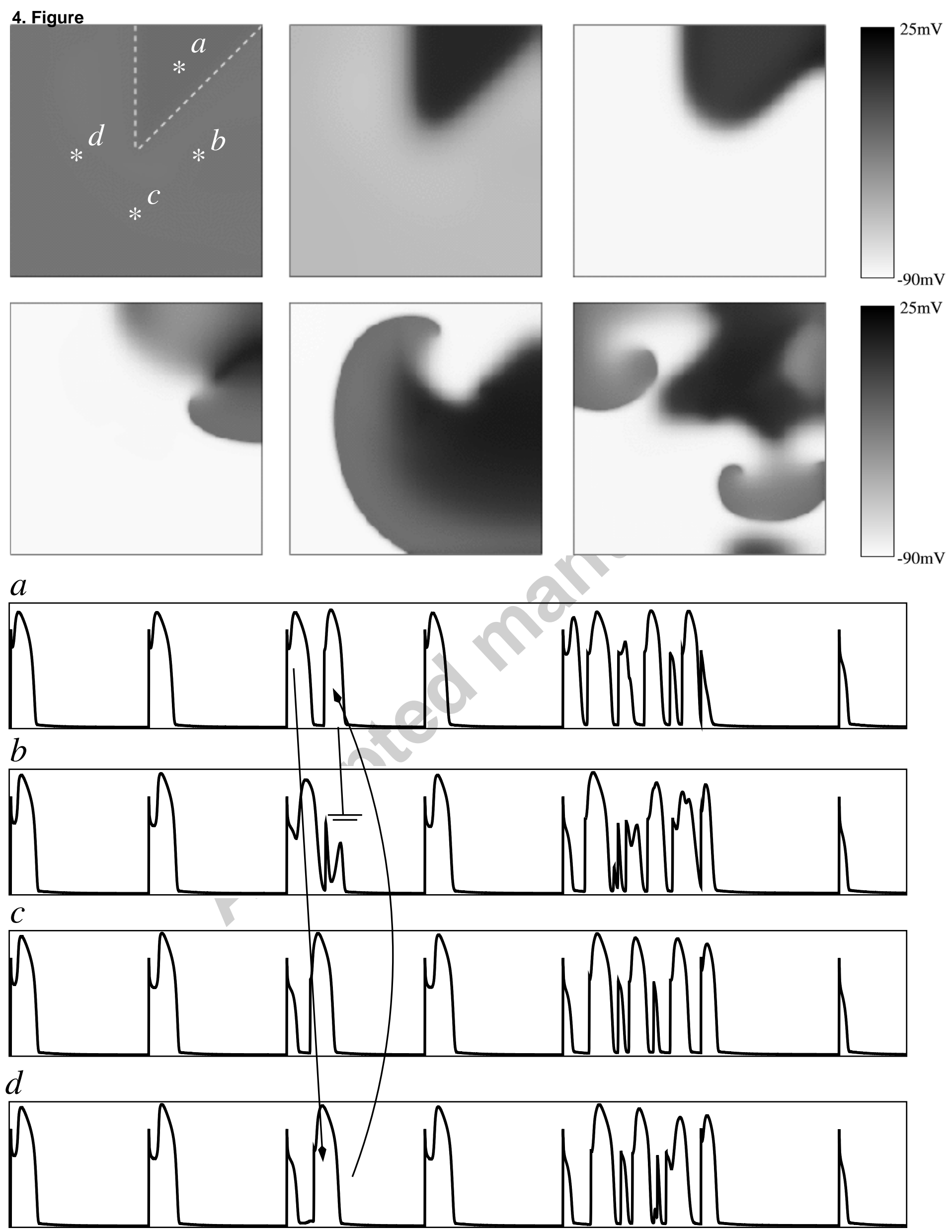
Table I: Effect of different changes in the parameters.

- Increasing sodium inactivation

- Increase in the percentage of domeless APs

- Decreased CV

- Appearance of windows in the probability of reexcitation, corresponding to the effect of an increase in the h gate closing rate $\beta_{\mathrm{h}}$.

- Constant probability of reexcitation, under an increase in the $h$ gate opening rate $\alpha_{\mathrm{h}}$.

- Increasing pacing period BCL

- Higher reexcitation probability

- Increasing $g_{\text {to }}$

- Loss of dome at $g_{\text {to }}$ between 0.6 and $1 \mathrm{mS} / \mu \mathrm{F}$, depending on the values of $\Gamma$ and $\mathrm{BCL}$

- Constant CV

- Change in $\mathrm{I}_{\mathrm{CaL}}$

- Increase in the probability of reexcitation with increase in $\mathrm{I}_{\mathrm{CaL}}$, up to a point in which the dome is recovered and reexcitations disappear. 